\title{
Vibrissa Movement Elicited by Rhythmic Electrical Microstimulation to Motor Cortex in the Aroused Rat Mimics Exploratory Whisking
}

\author{
Rune W. Berg ${ }^{1}$ and David Kleinfeld ${ }^{1,2}$ \\ ${ }^{1}$ Department of Physics and ${ }^{2}$ Neurosciences Graduate Program, University of California at San Diego, La Jolla, California 92093
}

Submitted 28 May 2003; accepted in final form 31 July 2003

Berg, Rune W. and David Kleinfeld. Vibrissa movement elicited by rhythmic electrical microstimulation to motor cortex in the aroused rat mimics exploratory whisking. J Neurophysiol 90: 2950-2963, 2003. First published August 6, 2003; 10.1152/jn.00511.2003. The rhythmic motor activity of the vibrissae that rodents use for the tactile localization of objects provides a model system for understanding patterned motor activity in mammals. Evidence suggests that neural circuitry in the brain stem provides rhythmic drive to the vibrissae. Yet multiple brain structures at higher levels of organization, including vibrissa primary motor cortex (M1), have direct projections to brain stem nuclei that are implicated in whisking. We thus asked whether output from M1 can control vibrissa movement on the approximately $10-\mathrm{Hz}$ scale of the natural rhythmic movement of the vibrissae. Our assay of cortical control made use of periodic intracortical microstimulation (ICMS) to excite a region of vibrissa M1 cortex in awake, behaving animals and measurements of the stimulus-locked electromyogram (EMG) in both the intrinsic and extrinsic muscles that drive the vibrissae. We observed that ICMS evoked a prompt activation of the extrinsic muscles and a delayed and prolonged response in the intrinsic muscles. The relative timing and shape of these waveforms approximates the EMG waveforms seen during natural exploratory whisking. We further observed prompt activation of the intrinsic muscles, an occurrence not seen during exploratory whisking. Despite the latter difference in muscular activation, the motion of the vibrissae evoked by periodic ICMS strongly resembled the motion during natural, exploratory whisking. Interestingly, the extent of the movement was proportional to the level of arousal, as quantified by the amplitude of hippocampal activity in the theta frequency band. We interpret these data as demonstrating that M1 cortex can, in principle, initiate the full pattern of whisking on a cycle-by-cycle basis in aroused animals. Beyond issues of natural motor control, our result may bear on the design of algorithms for neuroprosthetic control of motor output.

IN T R O D U C T I O N

The rat moves its vibrissae in a rhythmic manner as a means to sample tactile stimuli in its local environment (Brecht et al. 1997; Carvell and Simons 1990; Sachdev et al. 2002; Vincent 1912; Welker 1964; Wineski 1985). Input related to contact of the vibrissae with an object is transmitted along a hierarchy of sensorimotor neuronal loops. The innermost loop encompasses the brain stem trigeminal sensory nuclei and the facial motor nucleus, which contains the motoneurons that drive the mystacial musculature, whereas the outer level loop includes the dorsal thalamic nuclei and the primary sensory (S1) and motor

\footnotetext{
Address for reprint requests and other correspondence: D. Kleinfeld, Department of Physics 0319, University of California, 9500 Gilman Drive, La Jolla, CA 92093 (E-mail: dk@ physics.ucsd.edu).
}

(M1) cortices (Fee et al. 1997; Kleinfeld et al. 1999; O'Connor et al. 2002). Within the outer loop, the vibrissa area of M1 cortex receives a sensory input that correlates with vibrissa contact (Kleinfeld et al. 2002). Further, the onset of whisking in rat is preceded by an increase in overall spike rate among units in M1 cortex (Carvell et al. 1996). Thus although vibrissa M1 cortex is believed to participate in the control of whisking, the nature of this control has been largely unexplored.

Exploratory whisking as a prelude to vibrissa contact involves large, rhythmic sweeps of the vibrissae in the frequency range of 5 to $10 \mathrm{~Hz}$ (Table 1). The standard hypothesis for the control of whisking is that the movement is generated by a central pattern generator (CPG) located in the medulla. This hypothesis is based on the observation that aspects of rhythmic movement persist after sensory deafferentation (Berg and Kleinfeld 2003; Gao et al. 2001; Welker 1964), bilateral ablation of neocortex, or bilateral ablation of cerebellum (Semba and Komisaruk 1984). Consistent with the standard hypothesis is the notion that the vibrissa M1 cortex can control only the amplitude of the whisk cycles, or the angular set point for whisking, either of which tends to vary on the time scale of multiple whisking cycles (Fee et al. 1997). An alternative hypothesis is that the output from the M1 cortex has the capability to drive individual cycles of whisking. The drive can, in principle, involve cycle-by-cycle entrainment of a medullar CPG. Affirmation of this hypothesis implies that the thalamocortical loop can subsume control of whisking. It provides a means for vibrissa contact signals in S1 cortex to rapidly modulate motor output, as suggested by the interpretation of behavioral experiments on texture discrimination (Carvell and Simons 1995).

Our primary tool to distinguish among the above hypotheses is the induction of vibrissa movement by intracortical microstimulation (ICMS) of vibrissa M1 cortex during various states of arousal. ICMS is a powerful technique that has been used to map the musculotopy of M1 cortex in anesthetized animals (Asanuma 1989; Schieber 2001). In general, ICMS leads to small movements around specific joints, although it can lead to natural movement of the limbs (Graziano et al. 2002). For the specific case of the vibrissae, ICMS at different locations in M1 cortex can lead to different directions of movement of the vibrissae (Gioanni and Lamarche 1985; Sanderson et al. 1984), which is consistent with the control of vibrissa movements by two sets of muscles (Dorfl 1982). The intrinsic muscles, the

\footnotetext{
The costs of publication of this article were defrayed in part by the payment of page charges. The article must therefore be hereby marked "advertisement" in accordance with 18 U.S.C. Section 1734 solely to indicate this fact.
} 
TABLE 1. Center frequencies of exploratory whisking in rat

\begin{tabular}{|c|c|c|}
\hline $\begin{array}{l}\text { Frequency } \\
\qquad(\mathrm{Hz})\end{array}$ & Method(s) & Reference \\
\hline $5^{1}$ & $\begin{array}{l}\text { Spectral power of line scan } \\
\text { videography at } 2 \mathrm{kHz}\end{array}$ & Gao et al. (2001) \\
\hline $6^{2}$ & Videography at $60 \mathrm{~Hz}$ & Carvell and Simons (1995) \\
\hline $7^{2}$ & Mystacial EMG & Semba and Komisaruk (1984) \\
\hline $7^{2}$ & Spectral power of the EMG & Carvell et al. (1996) \\
\hline $8^{2}$ & Spectral power of the EMG & Fee et al. (1997) \\
\hline $8^{2}$ & Cinematography at $60 \mathrm{~Hz}$ & Welker (1964) \\
\hline $8^{2}$ & Mystacial EMG & Hamada et al. (1999) \\
\hline $8^{2}$ & Spectral power of the EMG & Carvell et al. (1991) \\
\hline $9^{2}$ & $\begin{array}{l}\text { Probability density of the peak } \\
\text { frequency of the spectral } \\
\text { power of the EMG }\end{array}$ & Berg and Kleinfeld (2003) \\
\hline $9^{2}$ & Spectral power of the EMG & O'Connor et al. (2002) \\
\hline $10^{2}$ & Videography at $60 \mathrm{~Hz}$ & Nicolelis et al. (1995) \\
\hline
\end{tabular}

1, Head-fixed preparation; 2, Free-ranging animals.

first set, are associated with individual vibrissa follicles. Their contraction leads to protraction (i.e., forward movement) of the vibrissae. The extrinsic muscles, the second set, are associated with the mystacial pad that contains and supports the follicles. Their contraction leads to a shift in the pivot point of the follicles and net retraction (i.e., backward movement) of the vibrissae (Berg and Kleinfeld 2003). Anatomical data make it likely that there are indirect projections from the M1 cortex to medullar nuclei that activate motoneurons for both muscle groups (Hattox et al. 2002; Miyashita et al. 1994), consistent with diverging projections from motor cortices to motoneurons in other species (Fetz and Cheney 1980; Huang et al. 1988; Schieber 2001).

Here we address motor control of the vibrissa by vibrissa M1 cortex in the awake animal. We ask: 1) can ICMS in the M1 cortex activate both the intrinsic and extrinsic muscles that drive the vibrissae?; 2) furthermore, can ICMS induce whisking movements that mimic those seen during normal rhythmic whisking behavior?; and 3) what effect, if any, does arousal have on the ICMS-evoked vibrissa movement? In particular, arousal is known to heighten the sensitivity of cortical neurons to their inputs (Buzsaki et al. 1988; Castro-Alamancos 2002a,b; Giovannini et al. 2001; Komisaruk and Olds 1968), a topic of recent review (Detari et al. 1999; McCormick and Bal 1997; Sarter and Bruno 2000), and thus may bear on motor control by cortex as well.

\section{METHODS}

Our subjects were 20 female Long Evans rats, 200 to $300 \mathrm{~g}$ in mass. Fifteen of these animals had EMG electrodes implanted in the upper branch of the extrinsic muscles (M. levator labii superioris) and in the intrinsic muscles in the mystacial pad. These animals also had microwire electrodes implanted in hippocampus to monitor local current flow. Toward the end of the experiments, 9 of the rats underwent a transection of the infraorbital branch of the trigeminal nerve (IoN) to abolish sensory feedback from the vibrissae. The overall sequence of experimentation was

Electrode Placement $\rightarrow$ Recovery $\rightarrow$ Training $\rightarrow$ Data Collection

$$
\rightarrow \text { IoN Transection } \rightarrow \text { Data Collection } \rightarrow \text { Histology }
$$

The care and all aspects of experimental manipulation of our animals were in strict accord with guidelines from the National Institute of
Health (NIH 1985) and have been approved by members of the local Institutional Animal Care and Use Committee.

\section{Electrodes}

The cortical stimulation electrodes consisted of 2 Teflon-coated etched Pt-Ir wires, each with an impedance of $2 \mathrm{M} \Omega$ at $\mathrm{f}=1 \mathrm{kHz}$ (no. PI0030.5A10, MicroProbe, Clarksburg, MD). The pair formed a bipolar stimulation electrode, with tips separated by $500 \mu \mathrm{m}$, that was held by adhesive in a 20-gauge stainless steel tube (Small Parts, Miami Lakes, FL) with adhesive (no. 420, Loctite, Rocky Hill, CT). The tip separation is small compared with the nearly 3-mm lateral extent of the vibrissa area of the M1 cortex (Kleinfeld et al. 2002; Neafsey 1990; Sanderson et al. 1984). Platinum-iridium was chosen to minimize neural damage from electrochemistry at the site of stimulation (Tehovnik 1996).

The hippocampal recording electrode consisted of a triplet of 50$\mu \mathrm{m}$-diameter Teflon-coated tungsten wires (A-M Systems, Carlsborg, WA) that was held by adhesive in a 3-mm-long, 25-gauge stainless steel tube (Small Parts). The 3 tips were separated so they spanned a total separation distance of $1 \mathrm{~mm}$, with the deepest electrode positioned in the dentate gyrus and the most shallow in CA1. The reference electrode was a single $50-\mu \mathrm{m}$-diameter Teflon-coated tungsten wire that was placed in the contralateral occipital lobe. We measured the local field potential (LFP) at each wire and report the differential measurement, or current source density (Freeman and Nicholson 1975), across the 3 wires, denoted as the $\nabla^{2} \mathrm{LFP}_{\text {hippo }}$. It is estimated as $\nabla^{2} \mathrm{LFP}_{\text {hippo }} \cong-[\mathrm{V}(\mathrm{z}+\Delta \mathrm{z}, \mathrm{t})-2 \mathrm{~V}(\mathrm{z}, \mathrm{t})+\mathrm{V}(\mathrm{z}-\Delta \mathrm{z}$, t) $] / \Delta z^{2}$, where $V(z)$ is the measured field potential in each of the 3 wires and $\Delta \mathrm{z}=500 \mu \mathrm{m}$.

The EMG electrodes were 50- $\mu$ m-diameter Teflon-coated tungsten wires (A-M Systems). The positioning in the intrinsic mystacial pad musculature and in the extrinsic muscles was performed as described previously (Berg and Kleinfeld 2003). We report the differential measurement between voltages across the 2 wires in each area, denoted as the $\nabla \mathrm{EMG}_{\text {intrinsic }}$ and the $\nabla \mathrm{EMG}_{\text {extrinsic }}$ for the $\nabla \mathrm{EMG}$ computed for the intrinsic versus extrinsic muscles, respectively.

\section{Surgery}

Aseptic surgery was performed with the rat anesthetized with ketamine $(0.05 \mathrm{mg}$ per $\mathrm{g}$ rat) and xylazine $(0.015 \mathrm{mg}$ per $\mathrm{g}$ rat), injected intraperitoneally. The head was held in a stereotaxic frame. The EMG electrodes were implanted first. Then, approximately 1-mm-diameter holes were drilled through the skull, the dura mater was carefully removed, and the stimulation electrode was implanted at the coordinates $(\mathrm{A}-\mathrm{P}, \mathrm{M}-\mathrm{L}, \mathrm{D}-\mathrm{V})=(2.0,1.5-2.0,1.0-1.2 \mathrm{~mm})$ with the 2 tips offset along the anterior-posterior (A-P) axis. The mediallateral coordinates correspond to the nominal depth of layer $\mathrm{V}$ in vibrissa M1 cortex. The gross placement was tested and confirmed by ICMS (Asanuma 1989) and, on successful placement, the electrode was permanently cemented (no. 1330 Ortho-Jet, Lang Dental, Wheeling, IL) to screws (no. 00-90-1/8'; Small Parts) placed nearby in the skull. The hippocampal recording electrodes were implanted at the coordinates $(-3.8,2.5,3.0 \mathrm{~mm})$ and secured to a neighboring screw and the reference electrode was implanted at coordinates $(-6,1,0-1$ $\mathrm{mm}$ ) and secured. All screws were connected to a common ground with 0.010 in. uncoated silver wire. All electrode leads were soldered (Stay Clean Flux; Harris, Cincinatti, $\mathrm{OH}$ ) to miniature 10-pin connectors (no. 2-mm, Samtec, New Albany, IN) in mounts of local design.

\section{Training}

The animals were allowed to recover for 5 days after surgery. They were then gentled and trained to locomote on a raised platform, as previously described (Berg and Kleinfeld 2003). Data from intact animals were collected on a daily basis for a period of $2 \mathrm{wk}$. In some experiments, diazepam (Baxter, Deerfield, NJ) was delivered as a 
subcutaneous bolus injection (1.2 mg per g animal). On completion of this phase of data collection, the IoN was transected in a subset of the animals, as described previously (Berg and Kleinfeld 2003). These animals recovered within 1 day after surgery, after which a second phase of data collection was initiated for a period of 2 days.

\section{ICMS}

The pair of stimulating electrodes in the vibrissa M1 cortex were connected to a bipolar, constant-current stimulation unit (no. 2100, A-M Systems). Stimuli consisted of a train of 35 bursts; the individual bursts consisted of 5 uniphasic pulses that were $100 \mu$ s is duration and spaced $2 \mathrm{~ms}$ apart (Donoghue and Wise 1982; Weiss and Keller 1994). The period between each burst was varied and the inverse of this period is referred to as the stimulation frequency. The entire stimulation sequence was repeated 20 times at each stimulation frequency in a given session. The magnitude of the current was typically 50-70 $\mu \mathrm{A}$, the standard threshold for behavioral responses (Tehovnik 1996). Visual inspection ensured that only the vibrissae, and not the limbs, neck, or other facial structures, moved in response to stimulation.

\section{Data collection}

Mystacial EMG activity and hippocampal LFP activity were amplified, filtered, and sampled at $8 \mathrm{kHz}$ with electronics of local design (Fee et al. 1996). The $\nabla$ EMG and $\nabla^{2} \mathrm{LFP}_{\text {hippo }}$ were calculated numerically from the digitized data. Videographs of the motion of the caudal row of vibrissae, acquired at 100 frames/s (MegaPlus ES310; Roper Scientific MASD, San Diego, CA), were obtained when the animal craned from a perch in search of a food tube, as described (Berg and Kleinfeld 2003).

\section{State of arousal}

The state of arousal was quantified in terms of the spectral components in the $\nabla^{2} \mathrm{LFP}_{\text {hippo }}$. The awake and aroused state was equated with 5 - to $10-\mathrm{Hz}$ rhythmic activity (i.e., $\theta$-band activity) (Green and Arduini 1954; Vanderwolf 1969). The sessile state was equated with large-amplitude irregular activity, generally in the $<5 \mathrm{~Hz}$ range or $\delta$-band. In all cases, the power spectra were estimated from recordings obtained just before the onset of intracortical microstimulation. Spectral power was estimated with the multitaper methods of Thompson using 5 Slepian tapers, for a spectral bandwidth of $1.7 \mathrm{~Hz}$, as described (Percival and Walden 1993).

\section{Histology}

At the end of each recording session, animals were deeply anesthetized and perfused with physiological saline, followed by $4 \%$ (wt/vol) paraformaldehyde in physiological saline. The brains were extracted, cryoprotected in physiological saline with $30 \%$ (wt/vol) sucrose, blocked in the vicinity of the electrode tracks, and sectioned with a sliding microtome in a coronal plane at a thickness of $25 \mu \mathrm{m}$. Each section was Nissl stained. Selected sections from each animal were photographed under brightfield illumination at low magnification. The depth of penetration was confirmed to lie between 900 and $1200 \mu \mathrm{m}$ below the pia in 9 of the 15 animals that had stimulating electrodes in the M1 cortex, recorded electrodes in the hippocampus, and EMG electrodes in the mystacial pad. For the example of Fig. 1, the depth is estimated to be $950 \mu \mathrm{m}$ below the pia.

\section{RES ULTS}

\section{Evoked vibrissa response in the anesthetized rat}

We first describe the evoked movement of the vibrissae in the ketamine-anesthetized animals as a means to connect the present experiments with established work. The stimulation
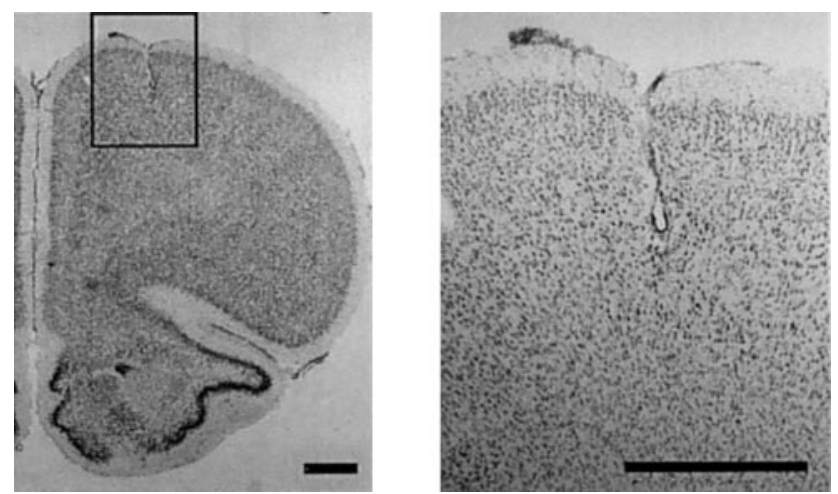

FIG. 1. Histological location of intracortical microstimulation (ICMS) electrodes in vibrissa primary motor cortex (M1) for representative animal (rat $\mathrm{n} 1$ ). A coronal section, $2.0 \mathrm{~mm}$ anteroposterior (A-P), that includes stimulation site in layer V, was Nissl stained and photographed under brightfield illumination. Scale bars: $1 \mathrm{~mm}$.

frequency for ICMS was chosen to be between 7 and $10 \mathrm{~Hz}$ to coincide with the frequency range of exploratory whisking (Table 1). The data from high-speed videographic measurements showed that the typical motion after each stimulus was a retraction of the vibrissae (Fig. 2, $A-D$ ). Further, we observed prompt, evoked activity in the $\nabla \mathrm{EMG}$ of both the intrinsic and extrinsic mystacial muscles, denoted the $\nabla \mathrm{EMG}_{\text {intrinsic }}$ and $\nabla \mathrm{EMG}_{\text {extrinsic }}$, respectively, from baseline values of zero (Fig. $2 D)$. Thus although muscular activity in both the intrinsic and extrinsic muscle groups was evoked by ICMS, the net mechanical effect was a retraction of the vibrissae (Fig. 2D, lower trace). This direction of the evoked movement was observed in 8 of 11 animals and is in agreement with past observations of retraction as the dominant direction of movement (Gioanni and Lamarche 1985; Sanderson et al. 1984).

The intrinsic and extrinsic muscles function in an agonist/ antagonist fashion in normal whisking (Berg and Kleinfeld 2003). The simultaneous contraction of the 2 groups is expected to produce opposing torques and thus the resultant movement of the vibrissae will occur in the direction of the greater torque. The observation of a net retraction (Fig. 2D) implies that the prompt activation of the extrinsic muscles produces a torque that is greater than that of the prompt activation of the intrinsic muscles.

\section{Evoked response in the awake but sessile rat}

Awake animals are known to have prolonged periods of lowered attention and immobility on the elevated platform (Kleinfeld et al. 1999; O'Connor et al. 2002). We refer to this as the sessile state. We observed that the ICMS-evoked motion of the vibrissae, as observed with videography, was solely retraction in the sessile state (Fig. 2, E-H). Further, the concomitantly measured $\nabla \mathrm{EMG}_{\text {intrinsic }}$ and $\nabla \mathrm{EMG}_{\text {extrinsic }}$ consisted solely of prompt responses (Fig. $2 H$ ). Thus the pattern of muscular activation and vibrissa motion in sessile animals is akin to that in animals under anesthesia. The one difference between the 2 cases was a shorter latency between the onset of the stimulus and that of the evoked $\nabla$ EMGs in the sessile $(17 \pm 2 \mathrm{~ms}$, mean $\pm \mathrm{SD} ; n=15$ animals $)$ versus anesthetized (23 $\pm 2 \mathrm{~ms} ; n=3$ animals) case (cf. Fig. 2, $D$ and $H$ ). 


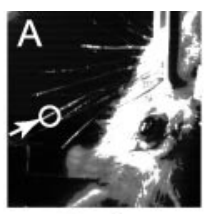

$\mathrm{t}=0$

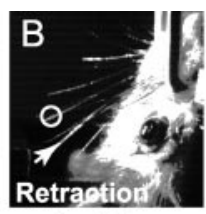

$\mathrm{t}=39 \mathrm{~ms}$

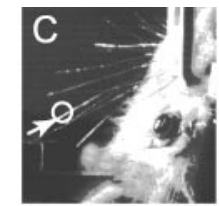

$\mathrm{t}=127 \mathrm{~ms}$

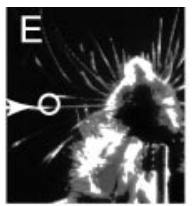

$\mathrm{t}=0$

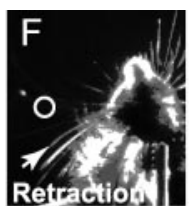

$\mathrm{t}=33 \mathrm{~ms}$

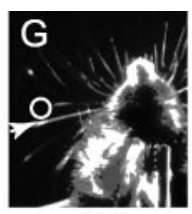

$\mathrm{t}=110 \mathrm{~ms}$
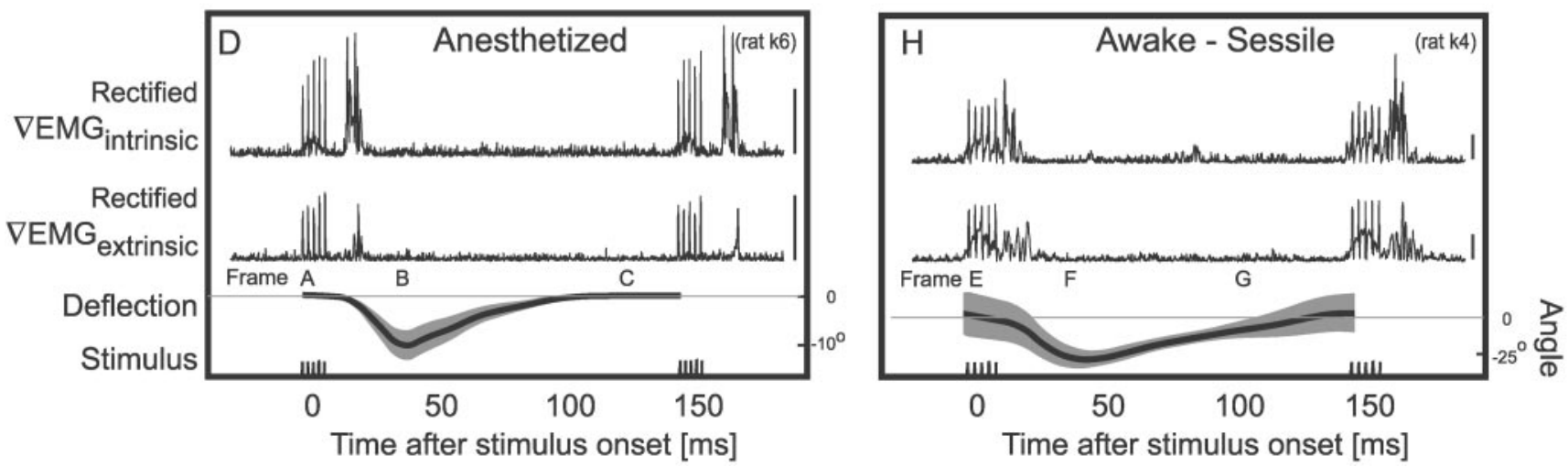

FIG. 2. Comparison of vibrissa movement and muscle activity in anesthetized vs. awake but sessile rat. $A-C$ : images of left side of face of anesthetized rat during ICMS to M1. Time indicated is from stimulus onset. Representative vibrissa, B1, is observed and marked with white arrow. White circle is fiducial. Position of this vibrissa is inside circle in $A$, retracted below circle in $B$, and back inside circle in C. D: simultaneous recording of intrinsic muscle activity (top trace) and that of extrinsic muscle activity (middle trace) in anesthetized rat. Bottom trace: stimulus-triggered average angular deflection of representative vibrissa, sampled every 10 $\mathrm{ms}$. Position of frames in time is indicated with frame letters $(A-C)$. Stimulus produces muscular activity in extrinsic muscle as well as in intrinsic muscle, but net movement is backward. Gray band is $\pm 1 \mathrm{SD}(n=8)$. Scale bar: $100 \mu \mathrm{V}$. $E-G$ : images of left side of face of rat in awake but sessile state during ICMS to M1. As in $A-C$, a representative vibrissa is observed; position of this vibrissa is inside circle in $E$, retracted below circle in $F$, and back inside circle in $G$. $H$ : simultaneous recording of intrinsic and extrinsic muscle activity in anesthetized rat. Bottom trace: stimulus-triggered average angular deflection of representative vibrissa. Position of frames in time is indicated with frame letters $(E-G)$.

\section{Evoked response in the sessile to aroused transition}

The sole presence of retraction of the vibrissae in sessile animals (Fig. $2 \mathrm{H}$ ) is at odds with the occurrence of full whisks that involve both retraction and protraction in awake and aroused animals (Berg and Kleinfeld 2003). To explore the potential change in whisking behavior between the evoked response for rats in the sessile state versus the aroused state, we collected trials in which the animal transitioned from one state to the other. For instance, the transition from immobility to arousal could be induced by lightly touching the tail of the sessile rat (Inglis and Fibiger 1995) (Fig. 3A). We observed the appearance of an additional, delayed and prolonged response in the $\nabla \mathrm{EMG}_{\text {intrinsic }}$ immediately after the transition from sessile to aroused behavior (cf. Fig. $3 A$, black vs. gray lines). The contrast between the form of the $\nabla \mathrm{EMG}_{\text {intrinsic }}$ in the sessile versus aroused state was particularly apparent in the stimulus-

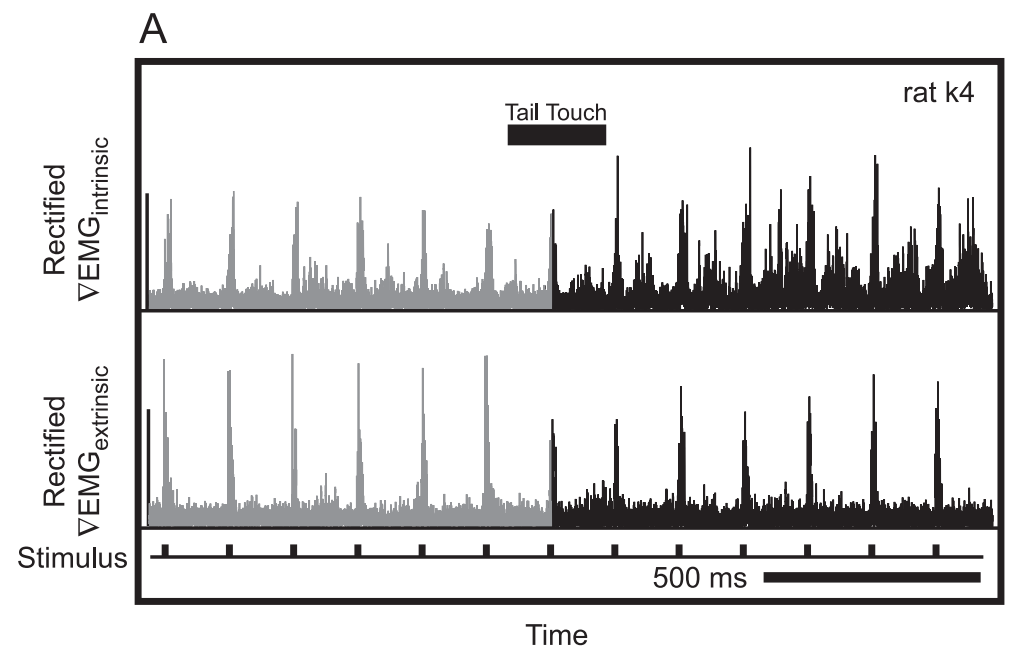

B

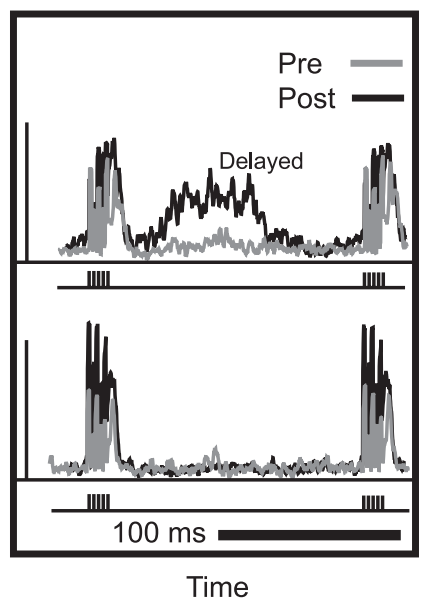

FIG. 3. Evoked VEMG response during transition from sessile to aroused state, as initiated by light touch of tail of representative animal. A: top and bottom traces show rectified $\nabla \mathrm{EMG}$ of intrinsic and extrinsic muscles, respectively. Bottom trace: ICMS events. Gray and black lines code data before and after tail touch, respectively. $B$ : stimulus-triggered averages of evoked $\nabla \mathrm{EMGs}$ from $A$. Note $\nabla \mathrm{EMG}$ for intrinsic muscle acquires a delayed response after tail touch. Vertical scale bars: $500 \mu \mathrm{V}(A)$; $100 \mu \mathrm{V}(B)$. 
triggered averages of the $\nabla \mathrm{EMG}$ before and after touch (cf. Fig. $3 B$, gray and black lines). In contrast to the case of the intrinsic muscles, there was no evidence for the delayed response in the extrinsic muscles (Fig. 3, $A$ and $C$ ). The differential behavior of the intrinsic versus extrinsic musculature was seen in all cases ( $n=15$ animals).

We consider next the relation of the new, delayed component in the $\nabla \mathrm{EMG}_{\text {intrinsic }}$ to an objective measure of arousal of the rat. We then shift our focus toward understanding how the ICMSevoked waveforms for the $\nabla \mathrm{EMG}_{\text {intrinsic }}$ and $\nabla \mathrm{EMG}_{\text {extrinsic }}$ relate to the movement of the vibrissae per se.

\section{ICMS-evoked motor output and arousal}

QUALITATIVE DEPENDENCY OF THE ICMS-EVOKED $\nabla$ EMG $_{\text {INTRINSIC }}$ ON AROUSAL. A standard measure of cortical arousal may be ascertained from the spectral content of the differential hippocampal field activity (Green and Arduini 1954; Vanderwolf 1969 1990), or $\nabla^{2} \mathrm{LFP}_{\text {hippo }}$ (METHODS). Arousal is signified by rhythmic activity in the 5- to $10-\mathrm{Hz}$ range, or $\theta$-band, whereas the lack of arousal or attention is signified by large-amplitude irregular activity that manifests itself in the 0 - to $5-\mathrm{Hz}$ range, or $\delta$-band. As a means to quantify the connection between the level of arousal and the nature of the muscular response to ICMS, we recorded field potential activity in the hippocampus (Robinson 1980) in a 3-s window before the onset of the ICMS paradigm. The frequency content of this prestimulus activity was determined from the spectral power of $\nabla^{2} \mathrm{LFP}_{\text {hippo }}$, denoted $S_{\text {hippo }}(f)$ and given by the square of the discrete Fourier transform of $\nabla^{2} \mathrm{LFP}_{\text {hippo }}$ averaged over multiple tapers. We further recorded the ongoing $\nabla$ EMG activity before stimulation and similarly calculated the spectral power in the $\nabla \mathrm{EMG}_{\text {intrinsic }}$.
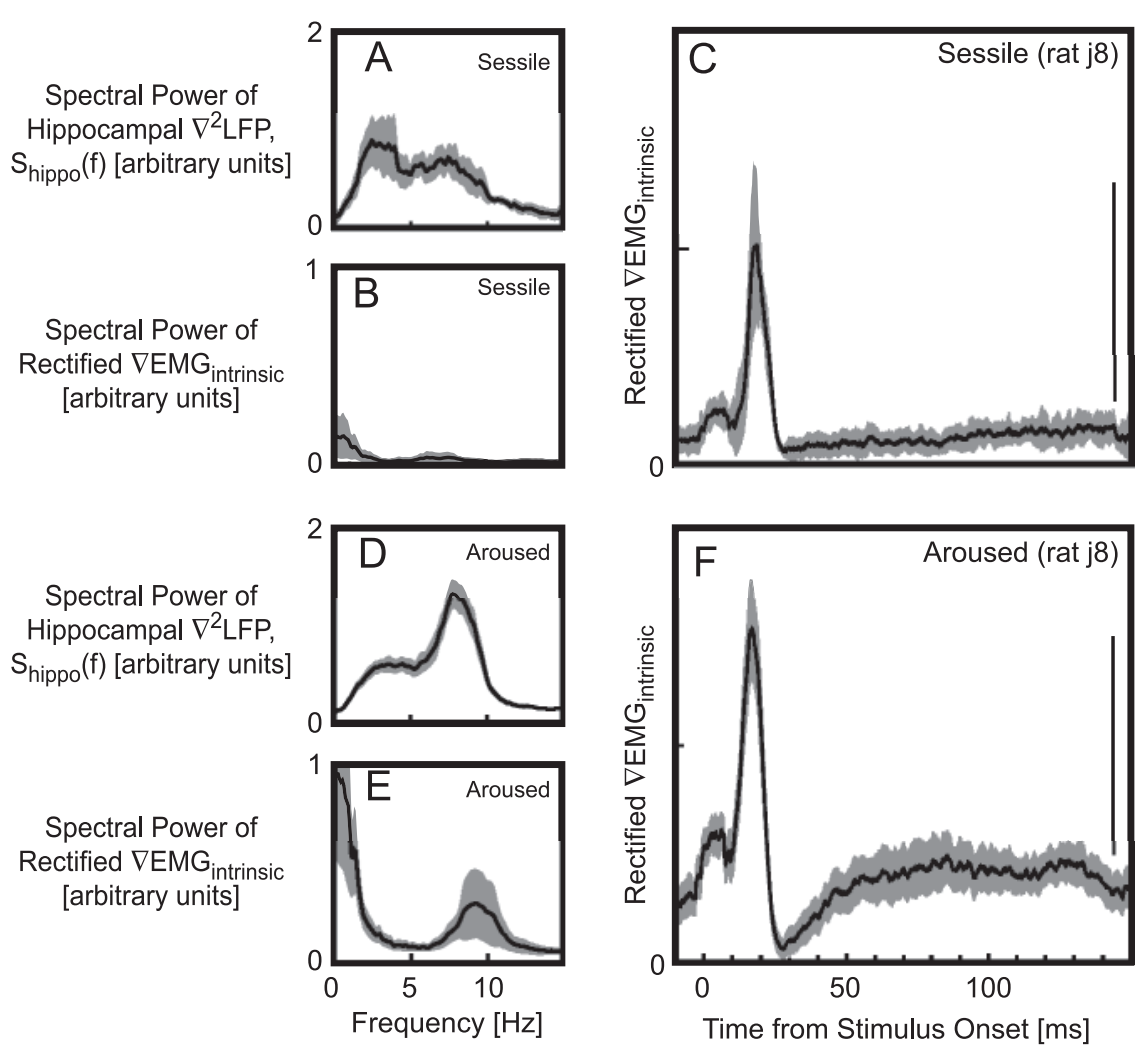

Example data illustrate key aspects of our results. We focus exclusively on the $\nabla \mathrm{EMG}$ for the intrinsic muscles, given that only this component showed a strong dependency on arousal. With the rat in the sessile state, the spectral power of the prestimulus $\nabla^{2} \mathrm{LFP}_{\text {hippo }}$ was broadly distributed between 2 and $10 \mathrm{~Hz}$ and did not show an obvious peak in the $\theta$-band range (Fig. 4A). Further, there was essentially no prestimulus $\nabla$ EMG activity (Fig. 4B). For this case, the trial-averaged $\nabla \mathrm{EMG}_{\text {intrinsic }}$ showed a prompt response, but did not show a delayed peak (Fig. 4C). In contrast to the data for the sessile case, in the aroused state the prestimulus $\nabla^{2} \mathrm{LFP}_{\text {hippo }}$ showed a broad oscillation that peaked near $8 \mathrm{~Hz}$ with the rat (Fig. 4D). Further, the ongoing whisking led to $\nabla$ EMG activity that peaked near $9 \mathrm{~Hz}$ (Fig. 4E). In response to periodic ICMS, the trial-averaged $\nabla \mathrm{EMG}_{\text {intrinsic }}$ showed a delayed peak (Fig. $4 F$ ), as seen in the previous example (Fig. 3B). Thus the delayed response in the activation of the intrinsic muscles was correlated with periods of strong hippocampal $\theta$-rhythm activity. Similar results were present in all cases ( $n=9$ animals). Further, the response of the vibrissa musculature to ICMS in aroused animals was independent of whether the animal was whisking before the onset of stimulation ( $n=9$ animals).

As a means to confirm the pairing of the delayed response in the $\nabla \mathrm{EMG}_{\text {intrinsic }}$ with arousal, we studied the nature of the ICMS response with animals in the normal, aroused state and after the systemic delivery of the pharmacological agent diazepam. This is a benzodiazepine that is known to have a calming effect (Cooper et al. 1996) and thus the administration of diazepam served as a surrogate for the sessile state. We observed that the delayed component in the stimulus-triggered average of the $\nabla \mathrm{EMG}_{\text {intrinsic }}$ was present in the control trials, yet it disappeared after administration of diazepam (Fig. 5, A
FIG. 4. Evoked intrinsic muscle response, $\nabla \mathrm{EMG}_{\mathrm{in}}{ }^{-}$ trinsic, in aroused vs. sessile state. $A$ : spectra power for hippocampal current source density, or $\nabla^{2} \mathrm{LFP}$, in sessile state. Gray regions represent $\pm 1 \mathrm{SD}$. Note spectrum lacks a prominent peak. $B$ : power spectra for mystacial vibrissa movement, or $\nabla \mathrm{EMG}_{\text {intrinsic }}$, in sessile state. Note almost complete absence of power at whisking frequencies. $C$ : ICMS-triggered average of evoked intrinsic muscular response in sessile state. Minimum value, or offset, has been subtracted from data. Note absence of delayed component. Scale bars: $50 \mu \mathrm{V}$. $D$ : spectra power for hippocampal $\nabla^{2}$ LFP in aroused state. Note peak centered at 7 to $9 \mathrm{~Hz}$. E: power spectra for mystacial vibrissa movement in aroused state. $F$ : ICMS-triggered average of evoked intrinsic muscular response in aroused state. Note prominent delayed component. Scale bars: $50 \mu \mathrm{V}$. 

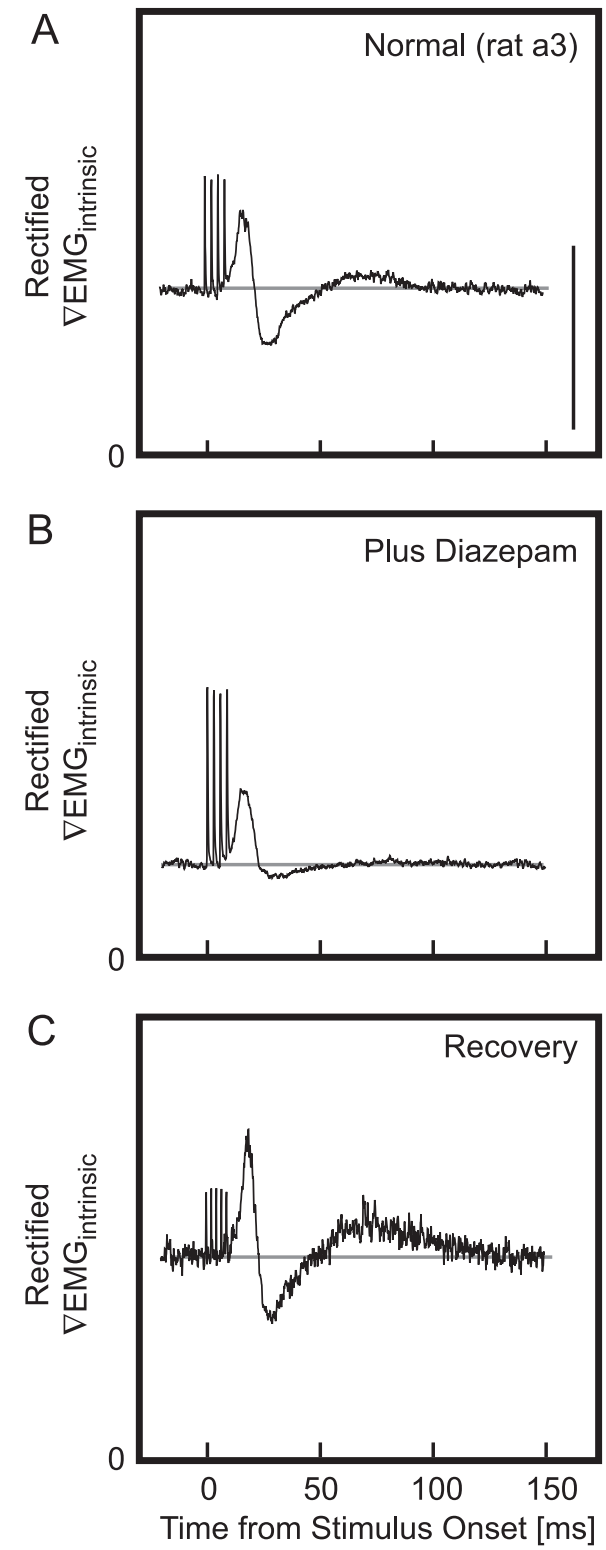

FIG. 5. Effect of administration of diazepam on evoked intrinsic muscle $\nabla$ EMG response in representative animal. A: stimulus-triggered average $(n=$ 100 stimuli) intrinsic muscle $\nabla E M G$ in aroused state. $B$ : same conditions as in $A$ except that rat is under systemic administration of diazepam ( $300 \mathrm{mg}$ for this $250 \mathrm{~g}$ animal). Delayed response is much less pronounced. $C$ : stimulustriggered average ( $n=20$ stimuli) intrinsic muscle $\nabla$ EMG taken following day in same animal. Animal has recovered and delayed response is regained. Scale bar: $25 \mu \mathrm{V}$.

and $B$ ). Thus diazepam led to a response similar to that seen with animals in the sessile state (cf. Figs. $4 C$ and $5 B$ ). Twentyfour hours later, the delayed response reappeared in the $\nabla \mathrm{EMG}_{\text {intrinsic }}$ (Fig. $5 C$ ). Similar results were obtained from the 2 other animals that we tested.

QUANTITATIVE DEPENDENCY OF THE ICMS-EVOKED $\nabla$ EMG $_{\text {INTRINSIC }}$ ON AROUSAL. The above analysis established that intracortical microstimulation induces $\nabla \mathrm{EMG}$ activity whose form depends on whether the animal was sessile or aroused. As a means to quantify this phenomena, and establish whether the delayed component in the $\nabla \mathrm{EMG}$ response is a continuous function of arousal or a threshold phenomenon, we considered the inte- grated value of the $\nabla \mathrm{EMG}_{\text {intrinsic }}$. We decomposed the integral into two parts (Fig. 6A):

1) The prompt response is defined as the integrated value of the $\nabla$ EMG within the interval from 10 to $30 \mathrm{~ms}$ after the onset of the stimulus, i.e.,

$$
\int_{\text {prompt }} \mathrm{dt} \nabla \mathrm{EMG} \equiv \int_{10 \mathrm{~ms}}^{30 \mathrm{~ms}} \mathrm{dt}\left[\nabla \mathrm{EMG}_{\text {intrinsic }}(\mathrm{t})-\min _{\mathrm{t}}\left\{\nabla \mathrm{EMG}_{\text {intrinsic }}(\mathrm{t})\right\}\right]
$$

where the constant term represents background activity that was uncorrelated with ICMS-evoked whisking.

2) The delayed response is defined as the integrated value of the $\nabla$ EMG from 30 to $150 \mathrm{~ms}$ after the onset of the stimulus, i.e.,

$$
\int_{\text {delayed }} \mathrm{dt} \nabla \mathrm{EMG} \equiv \int_{30 \mathrm{~ms}}^{150 \mathrm{~ms}} \mathrm{dt}\left[\nabla E M G_{\text {intrinsic }}(\mathrm{t})-\min _{\mathrm{t}}\left\{\nabla \mathrm{EMG}_{\text {intrinsic }}(\mathrm{t})\right\}\right]
$$

We next quantified the level of arousal in terms of the relative levels of power in the hippocampal response in the $\theta$ versus $\delta$-bands (Fig. $6 B$ ). Denoting the spectral power density of the hippocampal current flow as $S_{\text {hippo }}(f)$, we have

$$
\text { Arousal } \equiv \int_{5 \mathrm{~Hz}}^{10 \mathrm{~Hz}} \mathrm{dfS}_{\text {hippo }}(\mathrm{f}) / \int_{0}^{5 \mathrm{~Hz}} \mathrm{dfS}_{\text {hippo }}(\mathrm{f})
$$

We found that there was significant correlation of both the prompt and delayed integrated $\nabla \mathrm{EMG}_{\text {intrinsic }}$ responses with the level of arousal $(P<0.05$, Spearman correlation test, in 7 of 8 animals). Both responses are monotonic functions of the level of arousal and, phenomenologically, they appear to be proportional to the logarithm of our measure of arousal (Fig. 6, $C$ and $D$ ). The increase in the integrated response with increasing arousal was significantly greater for the delayed component, $\int_{\text {delayed }} \mathrm{dt} \nabla \mathrm{EMG}$, compared with the prompt component, $\int_{\text {prompt }} \mathrm{dt} \nabla \mathrm{EMG}$ (Fig. 6, cf. $C$ and $D$ ). In general, there was significant correlation of both the prompt and delayed integrated $\nabla \mathrm{EMG}$ responses with the level of arousal $(P<0.05$, Spearman correlation test, in 7 of 8 animals) (Fig. 6E). Further, there was a greater rate of the increase for the delayed component than for the prompt component with increasing arousal (Fig. $6 F$ ). These results show that the onset of the delayed component in the $\nabla \mathrm{EMG}_{\text {intrinsic }}$ appears to be a continuous yet relatively steep function of arousal.

VARIATION OF THE ICMS-EVOKED $\nabla$ EMG $_{\text {INTRINSIC }}$ WITH STIMULUS CURRENT. The dependency of the $\nabla$ EMG on arousal could, in principle, be related to the extent of depolarization and recruitment by ICMS (Stoney et al. 1968; Tehovnik 1996). In particular, the prompt $\nabla$ EMG components could arise from the output of directly activated layer $\mathrm{V}$ pyramidal neurons, whereas the delayed components could involve the transient activation of a recurrent circuit within M1 cortex. To the extent that the volume of cells activated by ICMS is a function of the stimulation current, this scenario could lead to a nonlinear dependency of the value of $\int_{\text {delayed }} \mathrm{dt} \nabla \mathrm{EMG}$ relative to that of $\int_{\text {prompt }} \mathrm{dt} \nabla \mathrm{EMG}$. To test for this possibility, we measured the integrated $\nabla E M G$ responses as a function of peak value of the stimulation current. We observed that both $\int_{\text {delayed }} \mathrm{dt} \nabla \mathrm{EMG}$ and $\int_{\text {prompt }} \mathrm{dt} \nabla \mathrm{EMG}$ increased as a linear function of the peak 

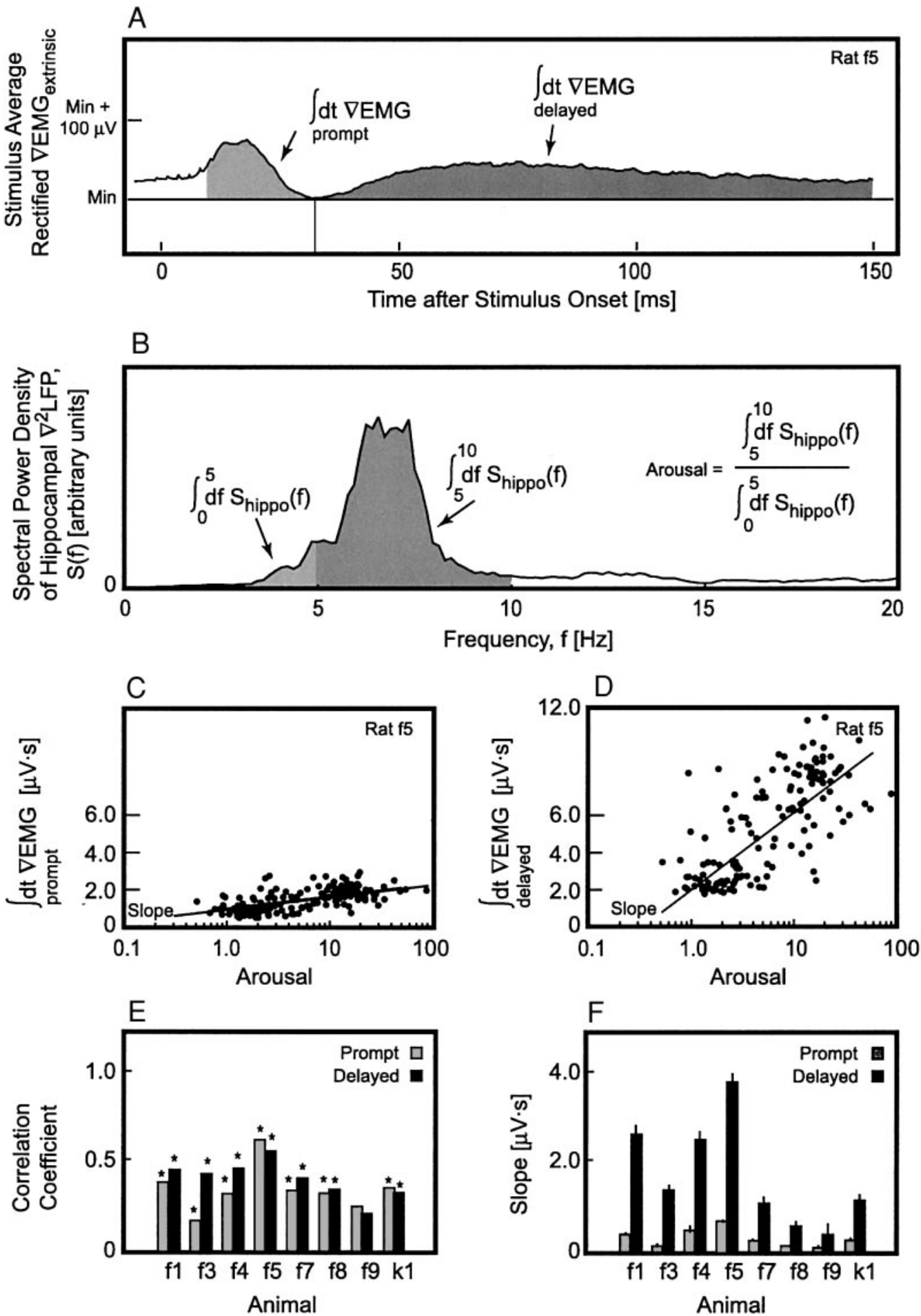

FIG. 6. Quantification of dependency of ICMS-evoked integrated $\nabla \mathrm{EMG}_{\text {intrinsic }}$ response on arousal. A: definition of integrated responses used for quantification of data; all integrations are with respect to minimum value of $\nabla \mathrm{EMG}_{\text {intrinsic }}$. Integrated prompt and delayed responses are established as integrated values of $\nabla \mathrm{EMG}_{\text {intrinsic }}$ from 10 to $30 \mathrm{~ms}$ (light gray area) and from 30 to 150 ms (dark gray area), respectively. $B$ : spectral power of 3-s window of hippocampal activity, $\nabla^{2} \mathrm{LFP}_{\text {hippo, }}$, before stimulation onset. From such data, arousal is measured as spectral power in $\theta$-band (i.e., power in 5 - to 10 - $\mathrm{Hz}$ band), over power in $\delta$-band (i.e., power in 1 - to $5-\mathrm{Hz}$ band). $C$ : integrated prompt $\nabla E M G$ response as a function of measure of arousal, plotted on logarithmic scale, for different whisking epochs with representative animal. Straight line is a best fit to data. $D$ : integrated delayed $\nabla$ EMG response as function of measure of arousal. E: Spearman correlation coefficients between evoked integrated $\nabla$ EMG response and arousal measure, as in $C$ and $D$, calculated for all animals. Columns marked "*”" represent correlation slopes significantly greater than zero $(P<0.05, t$-test). $F$ : slopes of linear fits of plots in $C$ and $D$, across multiple animals. 

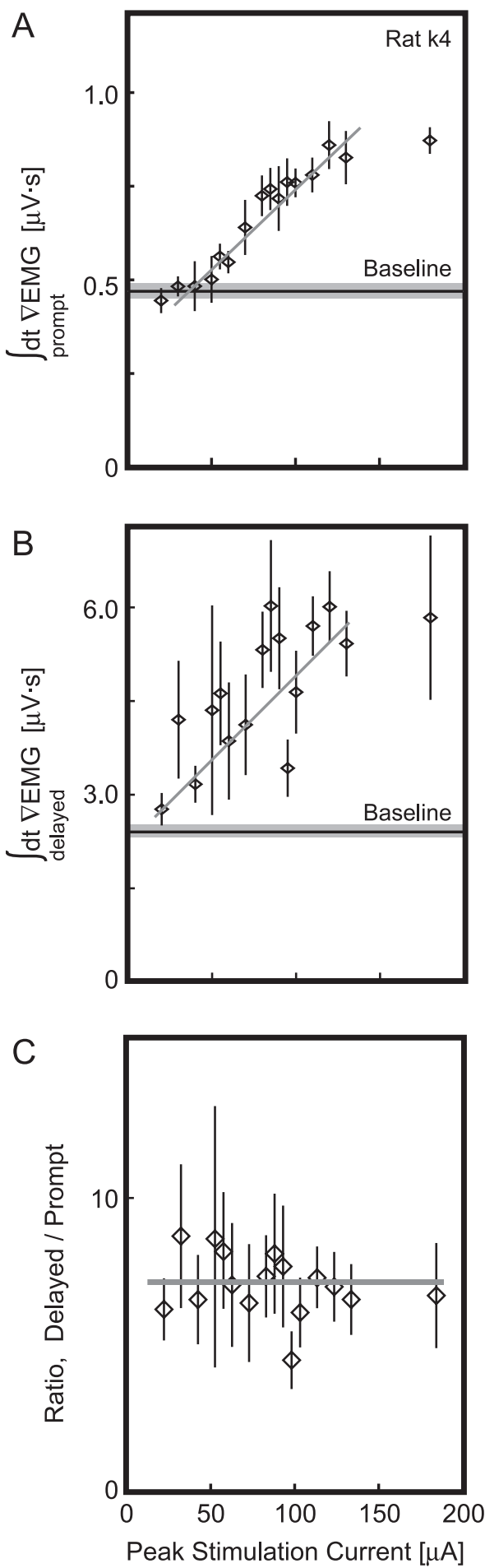

FIG. 7. Integrated ICMS-evoked $\nabla \mathrm{EMG}_{\text {intrinsic }}$ response as function peak stimulation current. $A$ : value of integrated prompt response vs. peak current. Black horizontal lines with gray background are minimum, or baseline, integrated $\nabla$ EMG background activity. $B$ : value of integrated delayed response vs. peak current. $C$ : ratio of integrated delayed to integrated prompt response as function of current intensity. Constant value is statistically significant.

value of the stimulation current (Fig. 7, $A$ and $B$ ). The ratio of the increase was essentially constant (Fig. 7C); that is, neither response was preferentially activated by higher currents. In general, the integrated $\nabla \mathrm{EMG}_{\text {intrinsic }}$ responses had a significant correlation with the magnitude of the applied current $(P<$
0.05 , Spearman correlation test, in 7 of 8 animals for the prompt response and 4 of 8 animals for the delayed response) and the ratio of the increase was constant (7 of 8 animals; compilation not shown). These data show that changes in the amplitude of the current do not induce a qualitative change in the muscular responses.

\section{Natural versus ICMS-evoked motor control in the aroused rat}

COMPARISON OF THE INTRINSIC AND EXTRINSIC VEMGS. Natural exploratory whisking consists of alternate activation of the intrinsic and extrinsic muscles (Fig. 8A) (Berg and Kleinfeld 2003). Activation of the intrinsic muscles, which protract the vibrissae, lasts nearly one-half of the whisking cycle (Fig. 8B), whereas that of the extrinsic muscles, which retracts the vibrissae, lasts for a fraction of the cycle (Fig. 8C). How well are these waveforms mimicked by those observed in ICMS-evoked whisking? The $\nabla \mathrm{EMG}$ for the intrinsic musculature contained a synchronous, prompt component that was not seen during natural exploratory whisking (Fig. $8 D$ ). Except for this extra component, the alternation of the delayed intrinsic response (Fig. $8 E$ ) and the prompt extrinsic response (Fig. $8 F$ ) compared well with the muscular response reported during exploratory whisking (cf. Fig. 8, $A$ and $D$ ). With regard to details of the individual waveforms, the broad delayed response for the ICMS-evoked $\nabla \mathrm{EMG}_{\text {intrinsic }}$ lined up with the peak of the broad $\nabla \mathrm{EMG}_{\text {intrinsic }}$ recorded during natural whisking (cf. Fig. $8, B$ and $E$ ). Further, the prompt response for the ICMS-evoked $\nabla \mathrm{EMG}_{\text {extrinsic }}$ was as narrow as the response seen during natural whisking (cf. Fig. 8, $C$ and $F$ ).

EVOKED VIBRISSA MOVEMENT IN THE AWAKE RAT. The antiphasic activation of the intrinsic and extrinsic muscles during exploratory whisking (Fig. 8A) leads to full sweeps of the vibrissae that encompass active protraction as well as retraction (Fig. 9A) (Berg and Kleinfeld 2003). How are sweeps generated by ICMS-evoked whisking? For the case of aroused versus sessile animals, the delayed response in the ICMSevoked $\nabla \mathrm{EMG}_{\text {intrinsic }}$ was the only additional contribution to the $\nabla$ EMG for either muscle group (cf. Fig. 4, $C$ and $F$ ). Thus the delayed component is likely to contribute to the forward movement of the vibrissae. To test this idea, animals were trained to perch and receive food from a tube as a means to maintain their head in a relatively fixed position for videography ( $n=4$ animals). The position and movement of the vibrissae were recorded during the application of ICMS (Fig. 9, $B-K$ ) and compared with the concurrently recorded $\nabla \mathrm{EMG}_{\text {intrinsic }}$; only this $\nabla \mathrm{EMG}$ component needed to be considered, given that the prompt response was similar for both muscle groups (cf. Fig. 8, $E$ and $F$ ).

We observed that the prompt $\nabla \mathrm{EMG}_{\text {intrinsic }}$ response was rapidly followed by retraction of the vibrissa (Fig. 9L). Only later, typically $45 \mathrm{~ms}$ after the stimulus onset, did the vibrissae slowly protract (Fig. 9K). An average of the videographic data across 4 animals showed that the prompt $\nabla$ EMG activity for either muscle group was predictive of the retraction of the vibrissae, whereas the delayed component of the $\nabla \mathrm{EMG}_{\text {intrinsic }}$ was associated with protraction (Fig. 9M). The delay between the ICMS-evoked $\nabla$ EMG activity and the physical movement of the vibrissae was about $25 \mathrm{~ms}$ (Fig. 9M). This value is in agreement with past results for the delay between the 

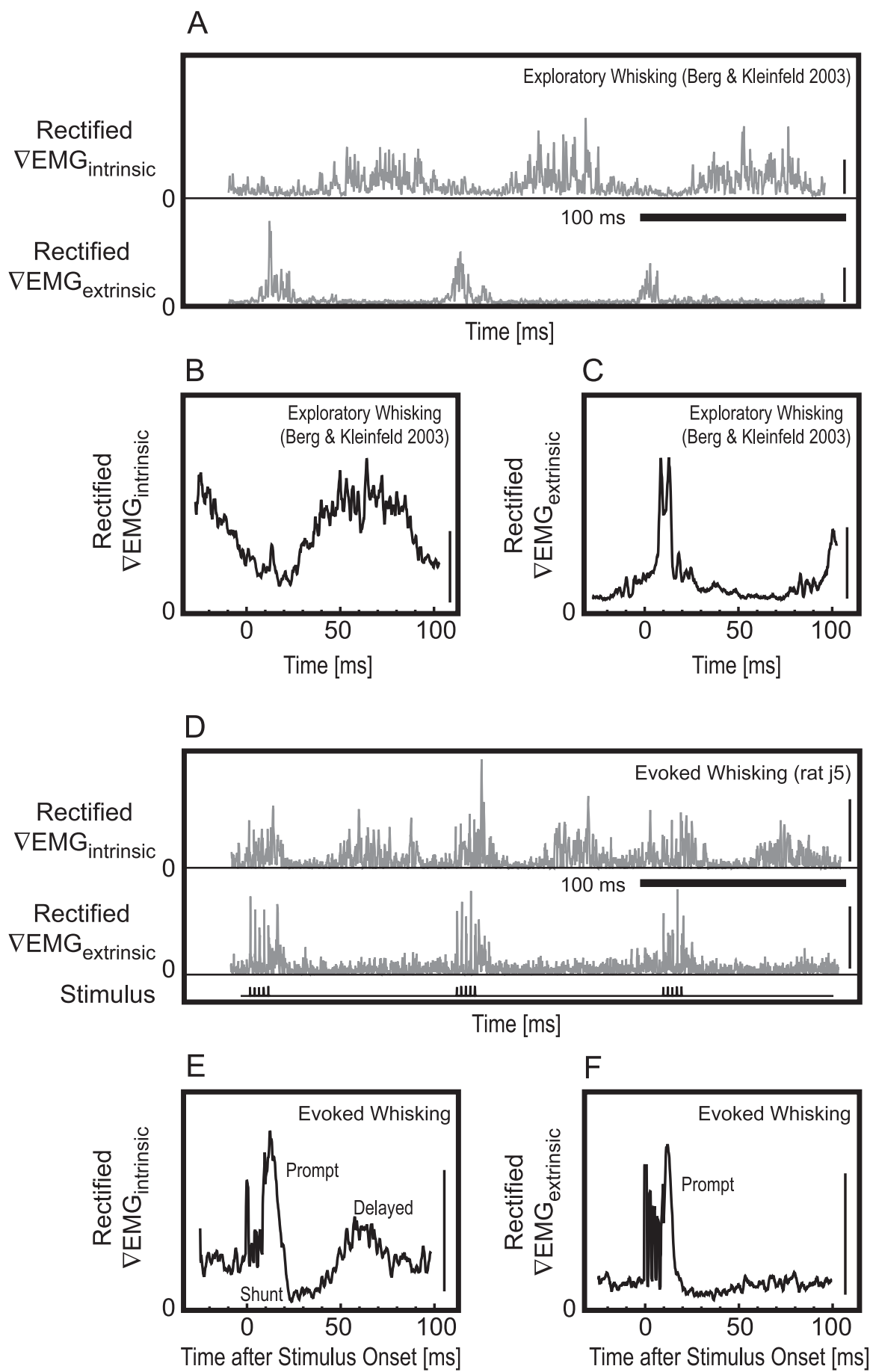

FIG. 8. Relation of simultaneously recorded $\nabla \mathrm{EMG}_{\text {intrinsic }}$ and $\nabla \mathrm{EMG}_{\text {extrinsic }}$ during exploratory whisking to ICMS-evoked $\nabla \mathrm{EMG}_{\text {intrinsic }}$ and $\nabla \mathrm{EMG}_{\text {extrinsic }}$ in awake and aroused animal. In both cases animals were perched and attempting to locate a food tube in front of perch. A: sample trace of intrinsic muscle rectified $\nabla \mathrm{EMG}$ (top trace) and the extrinsic rectified $\nabla$ EMG (bottom trace). Data used to generate this panel were from a previous study (Berg and Kleinfeld 2003). Scale bars: $100 \mu \mathrm{V} . B$ and $C$ : average of intrinsic and extrinsic muscle $\nabla$ EMG during exploratory whisking near $10 \mathrm{~Hz}$ ( $n=38$ cycles). Average was performed by maximizing overlap between peak of extrinsic responses of consecutive whisking cycles. Origin of time is arbitrary and chosen so that evoked (below) and natural peaks in $\nabla \mathrm{EMG}_{\text {extrinsic }}$ coincided. Scale bars: $50 \mu \mathrm{V}$. D: sample trace of evoked response of both intrinsic and extrinsic muscle rectified $\nabla$ EMGs. Scale bars: 100 $\mu \mathrm{V}$. $E$ and $F$ : stimulus-triggered average of intrinsic and extrinsic muscle $\nabla$ EMG, respectively $(n=35$ cycles). Scale bars: $50 \mu \mathrm{V}$. Evoked response of intrinsic muscle consists of a prompt as well as a delayed peak, whereas evoked extrinsic muscle response has only a prompt peak. Note that first $10 \mathrm{~ms}$ of data contains stimulus artifacts. $\nabla \mathrm{EMG}_{\text {intrinsic }}$ and the vibrissa motion during exploratory whisking (Berg and Kleinfeld 2003; Carvell et al. 1991). Although ICMS led to a synchronous, prompt component in the intrinsic musculature that was not seen during natural exploratory whisking, the overall vibrissa movements compared well with the movements during natural exploratory whisking (cf. Fig. 9, $L$ and $M$ with $9 A$ ).

EFFECT OF STIMULUS FREQUENCY. Exploratory whisks have center frequencies in the range of about 5 to $10 \mathrm{~Hz}$ (Table 1) or, equivalently, periods of 100 to $200 \mathrm{~ms}$. The 50- to 100-ms latency of the delayed response for the ICMS-evoked $\nabla \mathrm{EMG}_{\text {intrinsic }}$ (Fig. $8 E$ ) is thus shorter than the period for exploratory whisking. This implies that vibrissae M1 cortex can provide the drive for whisking at normal whisking frequencies. We addressed this possibility in terms of the latencies of muscle response evoked by ICMS, denoted as (Fig. 10A):

1) $t_{p}$ for latency to the peak of the prompt response.

2) $t_{d}$ for the latency to the peak of the delayed response. Example data illustrate key aspects of our results. Stimulustriggered averages of the $\nabla \mathrm{EMG}_{\text {intrinsic }}$ and $\nabla \mathrm{EMG}_{\text {extrinsic }}$ responses showed that there was no change in the amplitude of the prompt response nor in the latency to peak of the prompt response for stimulation frequencies $\leq 20 \mathrm{~Hz}$ ( $\mathrm{t}_{\mathrm{p}}$; Fig. 10, $A-F$ ). In contrast, the amplitude of the delayed response was sup- 

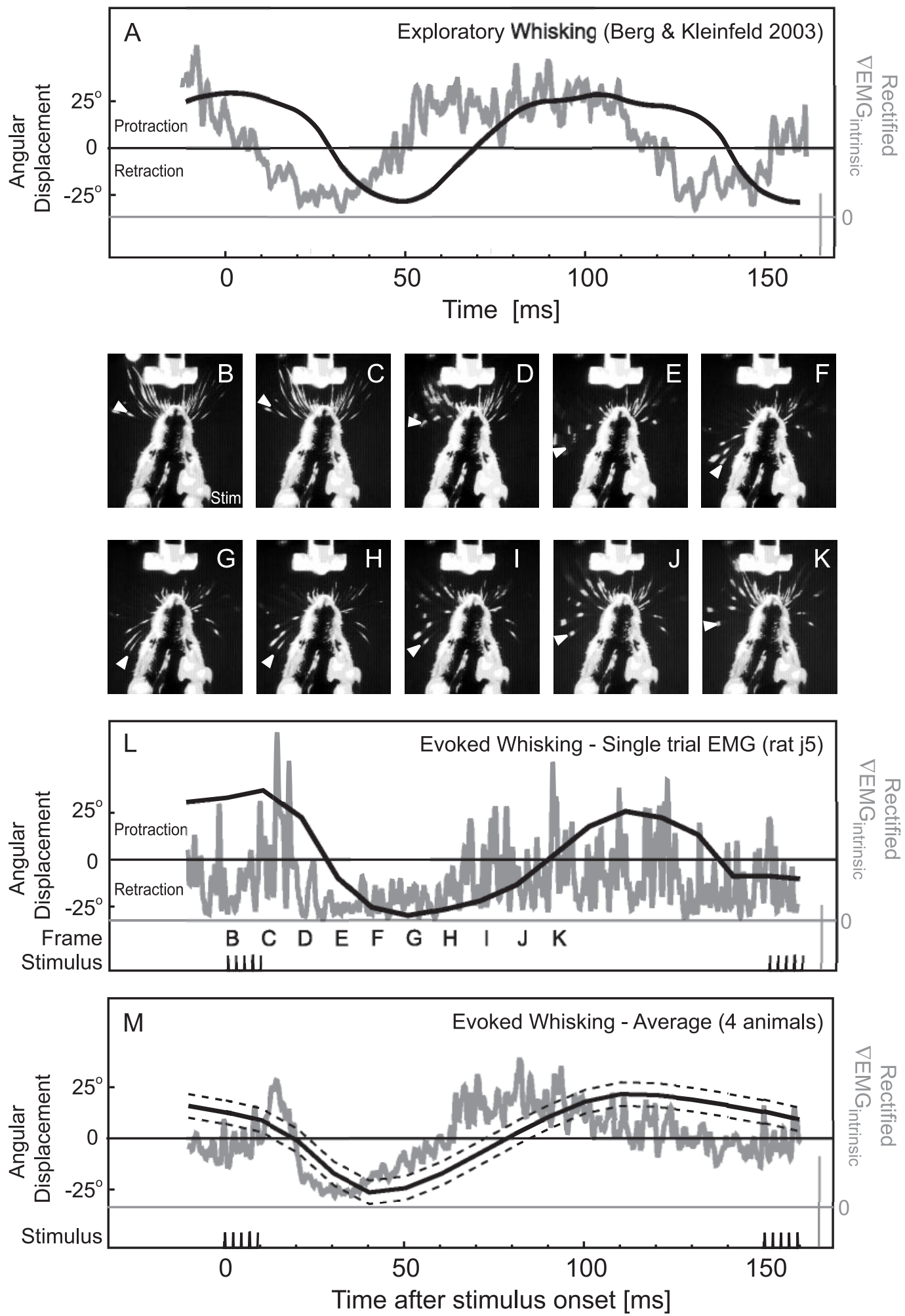

FIG. 9. Vibrissa movement and $\nabla \mathrm{EMG}_{\text {intrinsic }}$ activity during exploratory whisking in comparison with movement and $\nabla \mathrm{EMG}_{\text {intrinsic }}$ activity evoked by rhythmic intracortical microstimulation to $\mathrm{M} 1$ in awake rat. $A$ : vibrissa position and concomitant smoothed $\nabla \mathrm{EMG}_{\text {intrinsic }}$ during exploratory whisking, with a frequency near $10 \mathrm{~Hz}$, in free-ranging rat. Data used to generate this panel are from data set shown in Fig. 4 of Berg and Kleinfeld (2003). Origin of time is arbitrary and chosen so that evoked $(L$ and $M)$ and natural peaks in vibrissa protraction coincide. Scale bars: $100 \mu \mathrm{V}$. B-K: images of vibrissa movement in response to ICMS for first $90 \mathrm{~ms}$ after stimulation onset $(B)$ for representative animal; time between images is $10 \mathrm{~ms}$. Triangle in each frame indicates vibrissa, B1, whose angle was quantified over time. Animal was perched in front of a food tube. $L: \nabla E M G$ of left intrinsic muscles in a single stimulus event (gray) and position of vibrissa as derived from videography (black line; triangle in $B-K$ ); frames are indicated by their corresponding letters. Bottom marks indicate stimulation events. $M$ : stimulus-triggered average, over all trials and 4 animals ( $n=19,6,4$, and 9 trials for animals $\mathrm{j} 5, \mathrm{a} 3$, j8, and f1, respectively). Note that prompt retraction is consistently evoked by M1 stimulation, and is followed by delayed and prolonged protraction. All scale bars: $100 \mu \mathrm{V}$. 

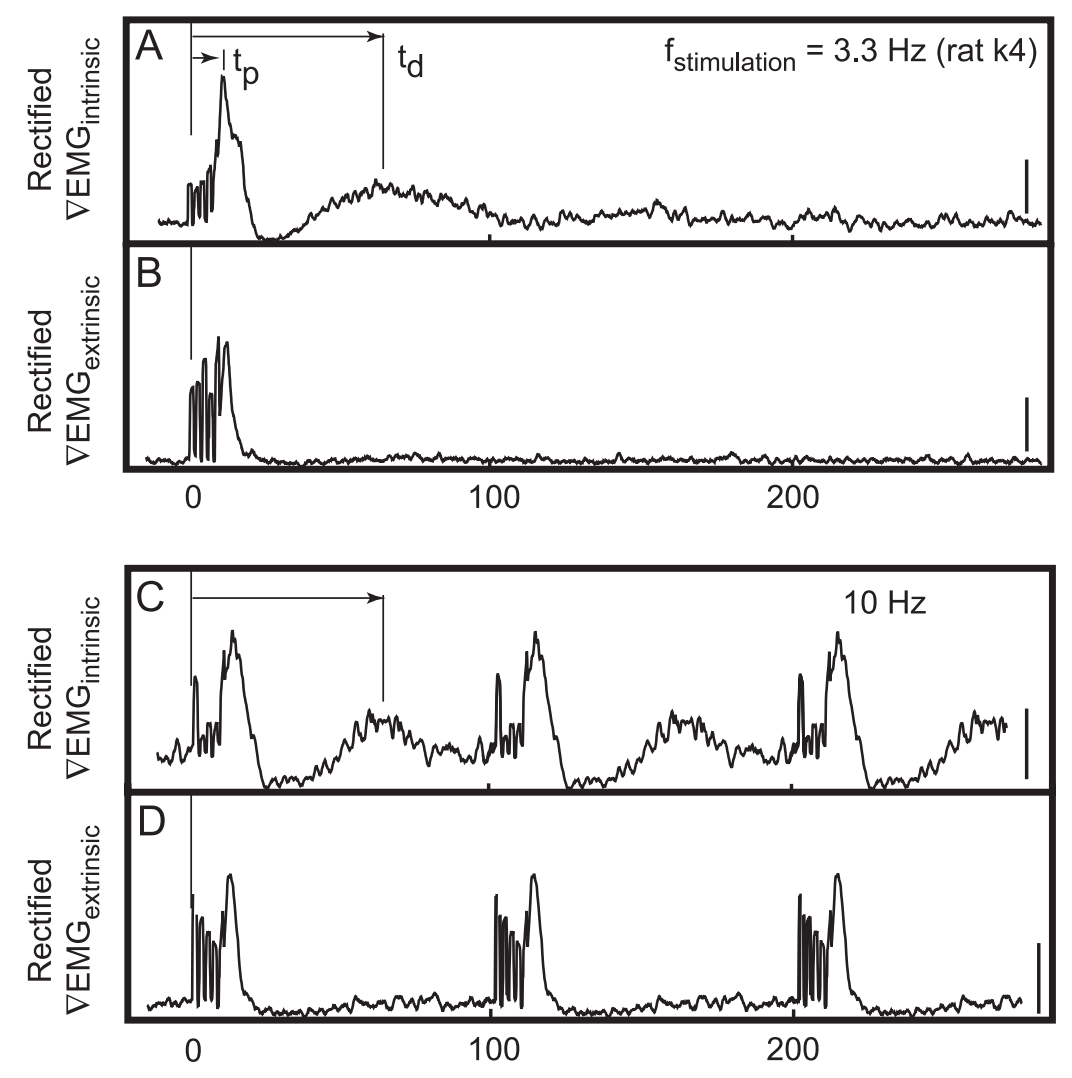

FIG. 10. Dependency of ICMS-evoked $\nabla \mathrm{EMG}_{\text {intrinsic }}$ and $\nabla \mathrm{EMG}_{\text {extrinsic }}$ on repetition frequency of stimulus. Shown are stimulus-triggered average evoked responses at 3 different frequencies $(n=35$ stimuli per trace). $A$ and $B$ : responses at a stimulation rate of $3.3 \mathrm{~Hz}$. Two latencies are indicated: $t_{p}$ for peak of prompt response and $t_{d}$ for peak of delayed response. $C$ and $D$ : responses at a stimulation rate of $10 \mathrm{~Hz}$. Note that peak of delayed response occurs with latency as for $3.3-\mathrm{Hz}$ stimulation. $E$ and $F$ : responses at a stimulation rate of $20 \mathrm{~Hz}$. Note that peak of delayed response has disappeared; it should have occurred nominally where arrow is, but has been eclipsed by preceding stimulus.

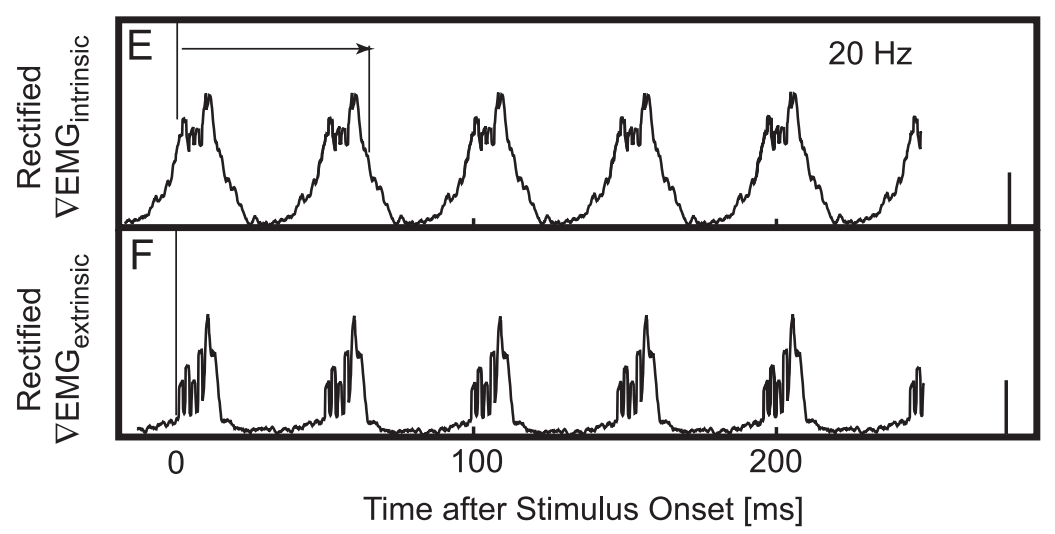

pressed at sufficiently high frequencies, as the prompt onset of one stimulus would fuse and interfere with the delayed response of the preceding stimulus (Fig. 10, $A, C$, and $E$ ). For the present example, the delayed response was lost for frequencies much above $10 \mathrm{~Hz}$.

The latency of the prompt response for the preceding example (Fig. 11A) and in general ( $n=8$ animals) was independent of the frequency of ICMS stimulation frequency. The mean value was $\left\langle\mathrm{t}_{\mathrm{p}}\right\rangle=17 \mathrm{~ms}$ (Fig. 11B). Further, although the latency of the delayed response showed a tendency to decrease with increasing stimulation frequency (Fig. 11C, dashed line), the trend was weak $(2 \mathrm{~ms} / \mathrm{Hz})$ and statistically significant in only 2 of 8 cases. In general, the latency of the delayed response could be taken as constant with a mean value of $\left\langle\mathrm{t}_{\mathrm{d}}\right\rangle=87 \mathrm{~ms}$ (Fig. 11D).

SENSORY FEEDBACK. The vibrissa sensory pathway is sensitive to self-generated movements of the vibrissae in the absence of contact (Fee et al. 1997). Thus the mechanical acceleration of the vibrissae that likely follows the prompt response to ICMS may, in principle, elicit a sensory signal that could trigger the delayed component of the $\nabla$ EMG response. The hypothetical dynamics provided motivation for experiments in which the infraorbital branch of the trigeminal nerve was transected after completion of the normal round of experiments. We observed that there were no apparent changes to the form of the $\nabla \mathrm{EMG}_{\text {intrinsic }}$ and $\nabla \mathrm{EMG}_{\text {extrinsic }}$ responses. Further, the latencies for the delayed components of $\nabla \mathrm{EMG}_{\text {intrinsic }}$ were unaffected by the deafferentation (cf. Fig. 11D, black and gray columns).

\section{I S C U S S I O N}

We studied the activation of the vibrissa musculature as well as the resultant movement of the vibrissae in the awake and aroused rat in response to rhythmic, intracortical microstimulation (ICMS) of the vibrissa area of primary motor (M1) 

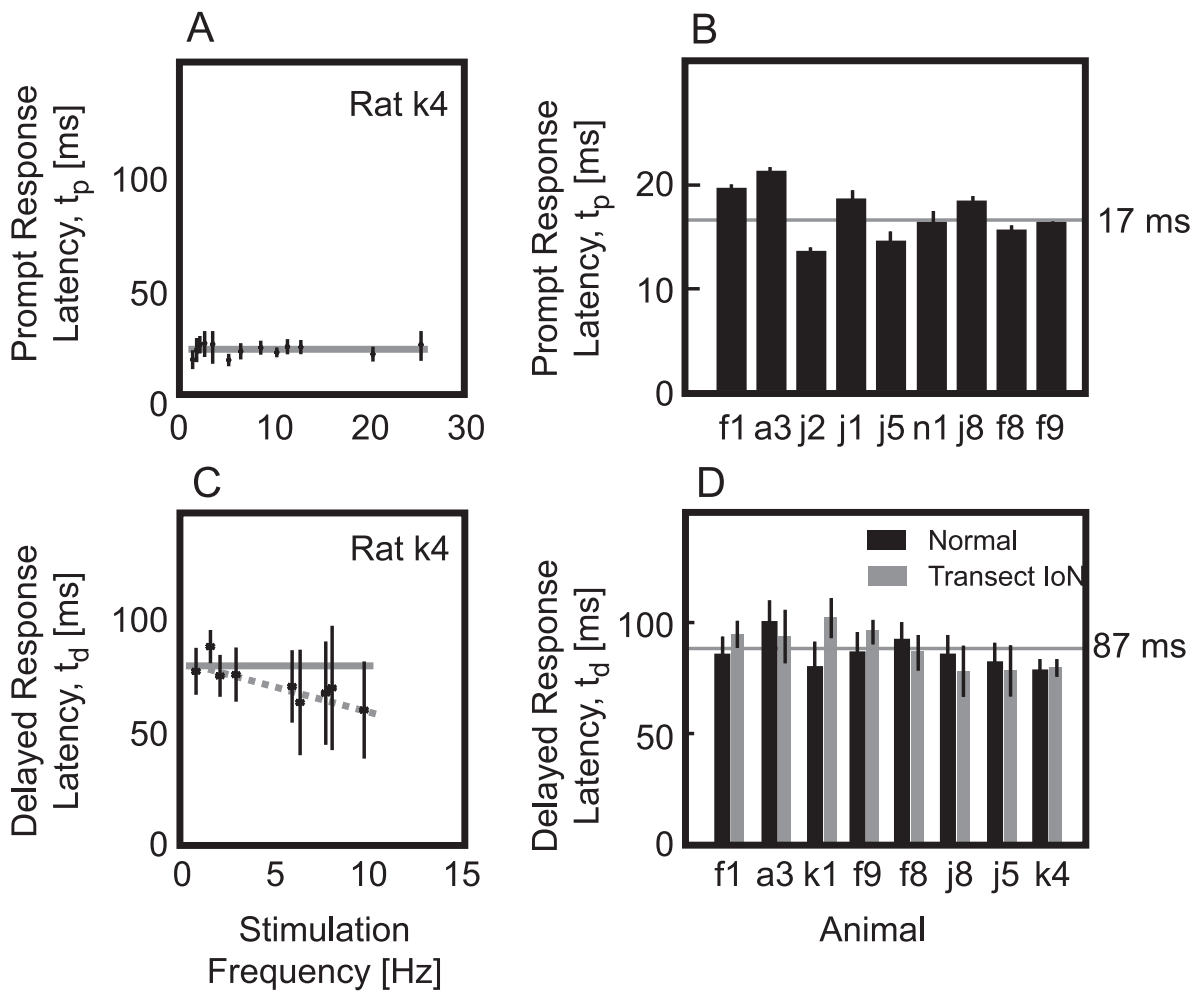

FIG. 11. Compilation of latencies, defined in Fig. $10 A$, for peaks of $\nabla \mathrm{EMG}_{\text {intrinsic }}$ responses. $A$ : latency for prompt response as a function of ICMS frequency for representative animal. Latencies were calculated from smoothed data. Solid line is a best fit to mean value for latency. $B$ : latencies of prompt responses across multiple animals. $C$ : latency for prompt response as a function of ICMS frequency for representative animal. Solid line is a best fit to mean value; note weak but significant frequency dependency for $t_{d}$ in this animal (dashed line). $D$ : latencies of delayed responses across multiple animals. Black columns represent data for intact animal and gray columns represent data taken from same animals after transection of infraorbital branch of trigeminal nerve (IoN). cortex (Fig. 1). We observed that ICMS leads to prompt responses in both the intrinsic and extrinsic muscles (Figs. 2, 3, 8, and 10); the former apply torque to the vibrissae, whereas the latter translate the mystacial pad (Berg and Kleinfeld 2003; Dorfl 1982; Wineski 1985). The net motion caused by the prompt response is retraction of the vibrissae (Figs. 2 and 9). We further observed that ICMS leads to a delayed and prolonged response in the intrinsic muscles (Figs. 4, 8, and 10), for which the motion is a delayed protraction of the vibrissa (Fig. 9). The combined effect of rhythmic ICMS in the awake and aroused animal is a back and forth sweep of the vibrissae that appears indistinguishable from natural exploratory whisking in the awake behaving rat (Fig. 9). The evoked motion occurs up to frequencies of $\geq 10 \mathrm{~Hz}$ (Fig. 10), consistent with the 5- to $10-\mathrm{Hz}$ frequency range of natural exploratory whisking (Table 1). Finally, evoked motion persists in the absence of sensory feedback (Fig. 11), similar to the case of exploratory whisking in the absence of contact (Berg and Kleinfeld 2003; Gao et al. 2001; Welker 1964). We thus conclude that vibrissa M1 cortex can, in principle, initiate individual whisks on the natural frequency of exploratory whisking.

We additionally observed that arousal leads to a qualitative change in the nature of the $\nabla \mathrm{EMG}$ signals and the movement in comparison with the same animals in the sessile state (Figs. 3 and 4). In the aroused state, ICMS elicits full cyclical sweeps of whisking that start with a backward movement (i.e., retraction) and are followed by long and slow forward movement, or protraction (Fig. 9). When the animal is sessile, sedated with diazepam, or anesthetized, only the prompt contraction of both muscle groups occurs (Fig. $7 F$ ), for which the net movement is retraction (Figs. 2 and 5).

\section{Mechanics of whisking}

The muscular dynamics in response to ICMS differ from that during natural exploratory whisking, in that the intrinsic and extrinsic muscle $\nabla$ EMGs now contain prompt, synchronous components (Fig. 8). Thus the intrinsic musculature is driven by a component that is not seen during natural exploratory whisking, in addition to the major delayed component that is similar to that seen during natural exploratory whisking (Fig. 9). Nonetheless, the net muscular activation under ICMS that leads to vibrissa movements is reminiscent of normal vibrissa movement (Figs. 8 and 9). Further, the amplitudes of the prompt and delayed components covary with the strength of the ICMS input (Fig. 7). We argue that the mechanical similarities between natural and ICMS-evoked whisking are sufficient to draw strong conclusions about the potential control of whisking by vibrissa M1 cortex.

\section{Response dependency on arousal}

The aroused state in the rat is characterized by strong oscillatory activity in the hippocampus that lies in the frequency range of 6 to $9 \mathrm{~Hz}$ (i.e., the $\theta$-rhythm). In contrast, the drowsy state has large-amplitude irregular activity in the frequency range of 1 to $4 \mathrm{~Hz}$ (i.e., the $\delta$-band) (Green and Arduini 1954; Komisaruk and Olds 1968; Vanderwolf 1969). We thus quantified the extent of arousal in terms of the spectral power in the hippocampal $\theta$-band. We observed that activation of both the prompt and delayed muscular responses increases roughly linearly with the logarithm of the spectral power (Fig. 6). Critically, the rate of increase of the delayed response is 3.3 times that of the prompt response. At low magnitudes of $\theta$-activity, the prompt response of both muscle groups is dominant (Fig. 4 ). As the magnitude of $\theta$-band activity increased, the delayed response sets in and ultimately leads to the appearance of a protraction phase in the ICMS-evoked whisking cycle in fully aroused animals (Fig. 4). Finally, we note that the increase in activation of the delayed versus prompt response is unlikely to be caused by an attention-mediated change in the electrical 
conduction (Klivington and Galambos 1968), and thus current spread, throughout the cortex. Indeed, an increase in current density by factors of 6 or more causes only equal increases in the delayed and prompt responses (Fig. 7), whereas the increase tied to arousal strongly favors the delayed response (Fig. 6).

The mechanism of sensory gating in association with arousal is well documented (Kobayashi and Isa 2002; McCormick and Bal 1997; Schridde and van Luijtelaar 2001). We report a direct correlation between motor gating and arousal. Two mechanisms may be responsible for this gating. One is that the gating originates in the pyramidal neurons in the cortex. In this scenario, arousal is associated with heightened levels of the activity in nuclear basalis magnocellularis, which elevates the release of the neuromodulator acetylcholine throughout the cortex (Buzsaki et al. 1988; Detari et al. 1999; McCormick and Prince 1986; Metherate et al. 1992; Sarter and Bruno 2000). The same mechanism is responsible for desynchronization of cortical activity with the rat in the aroused state (Buzsaki and Gage 1989; Detari et al. 1999; Sarter and Bruno 2000; Vanderwolf 1990). The second possibility is that the gating is caused by selective activation of brain stem nuclei. In this scenario, activation is associated with serotinergic modulation and facilitation of motor function by the Raphe nuclei (Dolphin and Greengard 1981; Jacobs and Fornal 1999, 1997; McCall and Aghajanian 1979). Selective activation of brain stem nuclei together with pharmacological blockers may be used to unravel the exact mechanism.

\section{Circuitry of exploratory whisking}

A common hypothesis is that rhythmic motor patterns are generated by a set of circuits, or burst generators (Pearson 2000), each of which is responsible for the contraction of specific muscles. The temporal coordination of these burst generators, and thus the coordination of motor behavior, is controlled centrally by a network, denoted a central pattern generator (CPG), that is robust yet flexible to suit several relevant motor tasks (Kleinfeld and Sompolinsky 1988; Marder and Calabrese 1996).

The circuitry of the motor pathway of the vibrissa system is outwardly consistent with the above architecture. The projections from M1 cortex to the medulla involve multiple pools of nuclei with direct connections to the vibrissa motoneurons in the facial nucleus (Fay and Norgren 1997; Hattox et al. 2002; Miyashita and Shigemi 1995). The burst generators could be reverberating circuits in these nuclei (Isokawa-Akesson and Komisaruk 1987; McCall and Aghajanian 1979; Mogoseanu et al. 1994). Further, noting that neuromodulators can enable bistable output in neurons (Dolphin and Greengard 1981; Hounsgaard and Kiehn 1989; Hounsgaard et al. 1988), the CPG may be toggled between an ON state and an OFF state by command signals from the cortex (Hattox et al. 2003). For example, tonic stimulation in M1 cortex is known to produce rhythmic jaw movement in rabbit (Lund et al. 1984; Nakamura and Katakura 1995).

An alternative mode of motor control is that M1 cortex subsumes the role of pattern generation. This scenario is consistent with the nested, closed-loop architecture of the vibrissa sensorimotor pathway (Ahissar and Kleinfeld 2003; Kleinfeld et al. 1999). This form of control is also suggested by exper- iments is which the output of units in M1 cortex are correlated with cyclic movements of limbs during locomotion (Beloozerova et al. 2003). Within this framework, the prompt and delayed responses may well involve different intermediate circuits in the medulla (Hattox et al. 2002). A likely possibility is that the prompt response involves a direct activation of vibrissae motoneurons, whereas the delayed response involves a path through resonant elements, possibly neurons in a CPG circuit.

We are grateful to $\mathrm{S}$. Venkatachalam for assistance with preliminary measurements, F. F. Ebner, A. Keller, A. B. Schwartz, and D. J. Simons for useful discussions, and H. P. Ziegler, along with J. Curtis, B. Friedman, S. B. Mehta, and D. Whitmer, for comments on early versions of the manuscript.

\section{I S C L OS URES}

This work was supported by National Institute of Mental Health Grant MH-59867.

\section{REFERENCES}

Ahissar E and Kleinfeld D. Closed loop neuronal computations: focus on vibrissa somatosensation in rat. Cereb Cortex 13: 53-61, 2003.

Asanuma H. The Motor Cortex. New York: Raven Press, 1989.

Beloozerova IN, Sirota MG, and Swadlow HA. Activity of different classes of neurons of the motor cortex during locomotion. J Neurosci 23: 1087 1097, 2003.

Berg RW and Kleinfeld D. Rhythmic whisking by rat: retraction as well as protraction of the vibrissae is under active muscular control. J Neurophysiol 89: 104-117, 2003.

Brecht M, Preilowski B, and Merzenich MM. Functional architecture of the mystacial vibrissae. Behav Brain Res 84: 81-97, 1997.

Buzsaki B and Gage FH. The cholinergic nucleus basalis: a key structure in neocortical arousal. In: Central Cholinergic Synaptic Transmission (Experientia Supplementum), edited by Frotscher M and Ulrich Misgeld U. New York: Springer-Verlag, 1989, p. 159-171.

Buzsaki G, Bickford RG, Ponomareff G, Thal LJ, Mandel R, and Gage FH. Nucleus basalis and thalamic control of neocortical activity in the freely moving rat. J Neurosci 8: 4007-4026, 1988.

Carvell GE, Miller SA, and Simons DJ. The relationship of vibrissal motor cortex unit activity to whisking in the awake rat. Somat Mot Res 13: 115-127, 1996.

Carvell GE and Simons DJ. Biometric analyses of vibrissal tactile discrimination in the rat. J Neurosci 10: 2638-2648, 1990.

Carvell GE and Simons DJ. Task- and subject-related differences in sensorimotor behavior during active touch. Somat Mot Res 12: 1-9, 1995.

Carvell GE, Simons DJ, Lichtenstein SH, and Bryant P. Electromyographic activity of mystacial pad musculature during whisking behavior in the rat. Somat Mot Res 8: 159-164, 1991.

Castro-Alamancos MA. Different temporal processing of sensory inputs in the rat thalamus during quiescent and information processing states in vivo. J Physiol 539: 567-578, 2002a.

Castro-Alamancos MA. Properties of primary sensory (lemniscal) synapses in the ventrobasal thalamus and the relay of high-frequency sensory input. J Neurophysiol 87: 946-953, 2002 b.

Cooper JR, Bloom FE, and Roth RH. The Biochemical Basis of Neuropharmacology. New York: Oxford Univ. Press, 1996.

Detari L, Rasmusson DD, and Semba K. The role of basal forebrain neurons in tonic and phasic activation of the cerebral cortex. Prog Neurobiol 58: 249-277, 1999.

Dolphin AC and Greengard P. Serotonin stimulates phosphorylation of protein I in the facial motor nucleus of rat brain. Nature 289: 76-79, 1981.

Donoghue JP and Wise SP. The motor cortex of the rat: cytoarchitecture and microstimulation mapping. J Comp Neurol 212: 76-88, 1982.

Dorfl J. The musculature of the mystacial vibrissae of the white mouse. J Anat 135: 147-154, 1982.

Fay RA and Norgren R. Identification of rat brainstem multisynaptic connections to the oral motor nuclei in the rat using pseudorabies virus. II. Facial muscle motor systems. Brain Res Rev 25: 276-290, 1997. 
Fee MS, Mitra PP, and Kleinfeld D. Variability of extracellular spike waveforms of cortical neurons. J Neurophysiol 76: 3823-3833, 1996.

Fee MS, Mitra PP, and Kleinfeld D. Central versus peripheral determinates of patterned spike activity in rat vibrissa cortex during whisking. $J$ Neurophysiol 78: 1144-1149, 1997.

Fetz EE and Cheney PD. Postspike facilitation of forelimb muscle activity by primate corticomotoneuronal cells. J Neurophysiol 44: 751-772, 1980.

Freeman JA and Nicholson C. Experimental optimization of current sourcedensity technique for anuran cerebellum. J Neurophysiol 38: 369-382, 1975.

Gao P, Bermejo R, and Zeigler HP. Vibrissa deaffentation and rodent whisking patterns: behavioral evidence for a central pattern generator J Neurosci 21: 5374-5380, 2001.

Gioanni Y and Lamarche M. A reappraisal of rat motor cortex organization by intracortical microstimulation. Brain Res 344: 49-61, 1985.

Giovannini MG, Rakovska A, Benton RS, Pazzagli M, Bianchi L, and Pepeu G. Effects of novelty and habituation on acetylcholine, GABA, and glutamate release from the frontal cortex and hippocampus of freely moving rats. Neuroscience 106: 43-53, 2001.

Graziano M, Taylor C, and Moore T. Complex movements evoked by microstimulation of precentral cortex. Neuron 34: 841-851, 2002.

Green JD and Arduini AA. Hippocampal electrical activity in arousal. J Neurophysiol 17: 533-547, 1954.

Hamada Y, Miyashita E, and Tanaka H. Gamma-band oscillations in the "Barrel Cortex" precede rat's exploratory whisking. Neuroscience 88: 667671, 1999.

Hattox AM, Li Y, and Keller A. Serotonin regulates rhythmic whisking. Neuron 39: 343-352, 2003.

Hattox AM, Priest CA, and Keller A. Functional circuitry involved in the regulation of whisker movements. J Comp Neurol 442: 266-276, 2002.

Hounsgaard J, Hultborn H, Jespersen B, and Kiehn O. Bistability of alpha-motoneurones in the decerebrate cat and in the acute spinal cat after intravenous 5-hydroxytryptophan. J Physiol 405: 345-367, 1988.

Hounsgaard $\mathbf{J}$ and Kiehn $\mathbf{O}$. Serotonine-induced bistability of turtle motoneurones caused by a nifedipine-sensitive calcium plateau potential. J Neurophysiol 414: 265-282, 1989.

Huang C-S, Sirisko M, Hiraba H, Murray G, and Sessle B. Organization of the primate face motor cortex as revealed by intracortical microstimulation and electrophysiological identification of afferent inputs and corticobulbar projections. J Neurophysiol 59: 796-818, 1988.

Inglis FM and Fibiger HC. Increases in hippocampal and frontal cortical acetylcholine release associated with presentation of sensory stimuli. Neuroscience 66: 81-86, 1995.

Isokawa-Akesson M and Komisaruk BR. Difference in projections to the lateral and medial facial nucleus: anatomically separate pathways for rhythmical vibrissa movement in rats. Exp Brain Res 65: 385-398, 1987.

Jacobs BL and Fornal CA. Serotonin and motor activity. Curr Opin Neurobiol 7: 820-825, 1997.

Jacobs BL and Fornal CA. Activity of serotonergic neurons in behaving animals. Neuropsychopharmacology 21: 9s-15s, 1999.

Kleinfeld D, Berg RW, and O'Connor SM. Anatomical loops and their relation to electrical dynamics in relation to whisking by rat. Somat Mot Res 16: 69-88, 1999.

Kleinfeld D, Sachdev RNS, Merchant LM, Jarvis MR, and Ebner FF. Adaptive filtering of vibrissa input in motor cortex of rat. Neuron 34: 1021-1034, 2002.

Kleinfeld D and Sompolinsky H. Associative neural network model for the generation of temporal patterns: theory and application to central pattern generators. Biophys J 54: 1039-1051, 1988.

Klivington KA and Galambos R. Rapid resistance shifts in cat cortex during click-evoked responses. J Neurophysiol 31: 565-573, 1968.

Kobayashi Y and Isa T. Sensory-motor gating and cognitive control by the brainstem cholinergic system. Neural Networks 15: 731-741, 2002.

Komisaruk BR and Olds J. Neuronal correlates of behavior in freely moving rats. Science 161: 810-813, 1968.

Lund JP, Sasamoto K, Murakami T, and Olsson KA. Analysis of rhythmic jaw movements produced by electrical stimulation of motor-sensory cortex of rabbits. J Neurophysiol 52: 1014-1029, 1984.

Marder E and Calabrese RL. Principles of rhythmic motor pattern generation. Physiol Rev 76: 687-717, 1996.

McCall RB and Aghajanian GK. Serotonergic facilitation of facial motoneuron excitation. Brain Res 169: 11-27, 1979.
McCormick DA and Bal T. Sleep and arousal: thalamocortical mechanisms. Annu Rev Neurosci 20: 185-215, 1997.

McCormick DA and Prince DA. Mechanisms of action of acetylcholine in the guinea-pig cerebral-cortex in vitro. J Physiol 375: 169-194, 1986.

Metherate R, Cox CL, and Ashe JH. Cellular bases of neocortical activation: modulation of neural oscillations by the nucleus basalis and endogenous acetylcholine. J Neurosci 12: 4701-4711, 1992.

Miyashita E, Keller A, and Asanuma H. Input-output organization of the rat vibrissal motor cortex. Exp Brain Res 99: 223-232, 1994.

Miyashita E and Shigemi M. The superior colliculus relays signals descending from the vibrissal motor cortex to the facial nerve nucleus in the rat. Neurosci Lett 195: 69-71, 1995.

Mogoseanu D, Smith AD, and Bolam JP. Monosynaptic innervation of facial motoneurons by neurones of the parvicellular reticular formation. Exp Brain Res 101: 427-438, 1994

Nakamura $\mathbf{Y}$ and Katakura N. Generation of masticatory rhythm in the brainstem. Neurosci Res 23: 1-19, 1995.

National Institutes of Health (NIH). Guide for the Care and Use of Laboratory Animals, NIH Publication 85-23. Bethesda, MD: National Institutes of Health, 1985.

Neafsey EJ. The complete ratunculus: output organization of layer V of the cerebral cortex. In: The Cerebral Cortex of the Rat, edited by Kolb B and Tees RC. Cambridge, MA: MIT Press, 1990.

Nicolelis MAL, Baccala LA, Lin RCS, and Chapin JK. Sensorimotor encoding by synchronous neural ensemble activity at multiple levels of the somatosensory system. Science 268: 1353-1358, 1995.

O'Connor SM, Berg RW, and Kleinfeld D. Coherent electrical activity along vibrissa sensorimotor loops during free whisking in rat. J Neurophysiol 87: 2137-2148, 2002.

Pearson KG. Neural adaptation in generation of rhythmic behavior. Ann Rev Physiol 67: 723-753, 2000.

Percival DB and Walden AT. Spectral Analysis for Physical Applications: Multitaper and Conventional Univariate Techniques. Cambridge, UK: Cambridge Univ. Press, 1993.

Robinson TE. Hippocampal rhythmic slow activity (RSA-theta): a critical analysis of selected studies and discussion of possible species-differences. Brain Res Rev 2: 69-101, 1980.

Sachdev RN, Sato T, and Ebner FF. Divergent movement of adjacent whiskers. J Neurophysiol 87: 1440-1448, 2002.

Sanderson KJ, Welker W, and Shambes GM. Reevaluation of motor cortex and of sensorimotor overlap in cerebral cortex of albino rats. Brain Res 292: 251-260, 1984.

Sarter M and Bruno JP. Cortical cholinergic input mediating arousal, attentional processing and dreaming: differential afferent regulation of the basal forebrain by telencephalic and brainstem afferents. Neuroscience 4: 933$952,2000$.

Schieber MH. Constraints on the somatotopic organization in the primary motor cortex. J Neurophysiol 86: 2125-2143, 2001.

Schridde $\mathbf{U}$ and van Luijtelaar G. The role of hippocampal theta activity in sensory gating in the rat. Physiol Behav 74: 257-266, 2001.

Semba K and Komisaruk BR. Neural substrates of two different rhythmical vibrissal movements in the rat. Neuroscience 12: 761-774, 1984.

Stoney SD, Thompson WD, and Asanuma H. Excitation of pyramidal tract cells by intracortical microstimulation: effective extent of stimulating current. J Neurophysiol 31: 659-669, 1968.

Tehovnik EJ. Electrical stimulation of neural tissue to evoke behavioral responses. J Neurosci Methods 65: 1-17, 1996.

Vanderwolf $\mathbf{C H}$. Hippocampal electrical activity and voluntary movement in the rat. Electroencephalogr Clin Neurophysiol 26: 407-418, 1969.

Vanderwolf $\mathbf{C H}$. An introduction to the electrical activity of the cerebral cortex: relations to behavior and control of subcortical inputs. In: The Cerebral Cortex of the Rat, edited by Kolb B and Tees RC. Cambridge, MA: MIT Press, 1990, p. 151-192.

Vincent SB. The function of the vibrissae in the behavior of the white rat. Behav Monogr 1: 7-81, 1912.

Weiss DS and Keller A. Specific patterns of intrinsic connections between representation zones in the rat motor cortex. Cereb Cortex 4: 205-214, 1994.

Welker WI. Analysis of sniffing of the albino rat. Behaviour 12: 223-244, 1964

Wineski LE. Facial morphology and vibrissal movement in the golden hamster. J Morphol 183: 199-217, 1985. 